\title{
Switchgrass establishment and growth for biofuels and carbon sequestration on reclaimed mine lands in Appalachia
}

\author{
Travis L. Keene \\ West Virginia University
}

Follow this and additional works at: https://researchrepository.wvu.edu/etd

\section{Recommended Citation}

Keene, Travis L., "Switchgrass establishment and growth for biofuels and carbon sequestration on reclaimed mine lands in Appalachia" (2010). Graduate Theses, Dissertations, and Problem Reports. 3034. https://researchrepository.wvu.edu/etd/3034

This Thesis is protected by copyright and/or related rights. It has been brought to you by the The Research Repository @ WVU with permission from the rights-holder(s). You are free to use this Thesis in any way that is permitted by the copyright and related rights legislation that applies to your use. For other uses you must obtain permission from the rights-holder(s) directly, unless additional rights are indicated by a Creative Commons license in the record and/ or on the work itself. This Thesis has been accepted for inclusion in WVU Graduate Theses, Dissertations, and Problem Reports collection by an authorized administrator of The Research Repository @ WVU. For more information, please contact researchrepository@mail.wvu.edu. 


\title{
SWITCHGRASS ESTABLISHMENT AND GROWTH FOR BIOFUELS AND CARBON SEQUESTRATION ON RECLAIMED MINE LANDS IN APPALACHIA
}

\author{
Travis L. Keene \\ Thesis submitted to the \\ College of Agriculture, Natural Resources and Design \\ at West Virginia University \\ in partial fulfillment for the requirements for the degree of \\ Master of Science \\ In \\ Plant and Soil Science \\ Committee: \\ Dr. Jeffrey Skousen, Chair \\ Dr. Louis McDonald \\ Dr. Alan Sexstone
}

Division of Plant and Soil Sciences

West Virginia University

Morgantown, WV

2010 


\begin{abstract}
Switchgrass Establishment And Growth For Biofuels And Carbon Sequestration On Reclaimed Mine Lands In Appalachia

Travis L. Keene
\end{abstract}

Climate change mitigation and the high cost of transportation fuels have created an interest in utilizing biofuels to supplement the nation's energy portfolio. Switchgrass (Panicum virgatum) has been suggested as a possible biofuel feedstock because of its ability to produce large amounts of biomass over a wide range of growing conditions and its ability to sequester atmospheric carbon (C) into stable soil organic carbon. Appalachia has the potential to become a center of biofuel production with its large expanses of reclaimed mine land. Switchgrass production on surface mine land offers the opportunity to increase the land resources devoted to energy crops without decreasing land resources devoted to food and livestock feed production. To examine the feasibility of establishing switchgrass as an initial reclamation species, three varieties of switchgrass were planted into 0.4 ha plots at three different surface mines in WV. Each variety was replicated three times for a total of nine plots at each site. Planting was conducted in May of 2008. The varieties Carthage, Cave-in-Rock and Shawnee were chosen for their favorable growing characteristics and adaptation to WV climate. Cover and frequency data from the first growing season showed switchgrass successfully established at all three sites with both broadcast planting and hydroseeding. Cover and biomass data from the second growing season showed that switchgrass performed much better on finer textured soils with higher amounts of soil organic matter, such as was seen with soils reclaimed with municipal biosolids. Biomass averaged $207 \mathrm{~kg} \mathrm{ha}^{-1}$ at the Hobet 21 site, $784 \mathrm{~kg} \mathrm{ha}^{-1}$ at the Coal-Mac site, and 4,501 $\mathrm{kg} \mathrm{ha}^{-1}$ at the Hampshire Hill site. The Cave-in-Rock variety yielded the highest biomass at both Coal-Mac and Hobet 21. Relatively poor performance of switchgrass at Coal-Mac and Hobet 21 indicated that switchgrass, while tolerant of poor soils once established, is unsuited for initial reclamation of nutrient poor and rocky minesoils where good cover and biomass production are expected within one or two years of planting.

Another reclaimed mine site in southwestern PA was selected to study $\mathrm{C}$ sequestration under different-aged switchgrass stands on mined and unmined soils. Fourteen stands of switchgrass were measured across a chronosequence of establishment on mined and unmined soils ranging from 1991 to 2008 . Soil organic C was $1.7 \%$ for the $0-15 \mathrm{~cm}$ depth and $0.8 \%$ for the 15-30 cm depth and was identical for both mined and unmined soils. Switchgrass biomass was higher on unmined plots than mined plots with yields of $8745 \mathrm{~kg} \mathrm{ha}^{-1}$ and $6024 \mathrm{~kg} \mathrm{ha}^{-1}$, respectively. Biomass was not correlated with stand age. Soil organic $\mathrm{C}$ was not correlated with the age of the established switchgrass stands suggesting that either the soils were in equilibrium with respect to $\mathrm{C}$ or that switchgrass was sequestering $\mathrm{C}$ at a rate indistinguishable from the previous cool season grass cover. Other factors were correlated to soil organic C. On mined 
areas, $\mathrm{pH}$ was highly correlated with both soil organic $\mathrm{C}$ and biomass. This suggests that acidity was a limiting factor and that managing soil fertility through liming treatments was effective at both increasing soil organic $\mathrm{C}$ and switchgrass biomass.

The chemi-thermal method of Ussiri and Lal (2008) was used to distinguish between C from soil organic, carbonaceous rock, and inorganic carbonate sources. A methodological evaluation of this method was performed to test the hypothesis that $\mathrm{C}$ was being removed from shale and coal mixtures often found in mine soils. The removal of geogenic $\mathrm{C}$ with this method would cause an overestimation of soil organic $\mathrm{C}$. The chemi-thermal method was performed on pure coal and three mixtures of coal and shale. The pure coal lost $20 \%$ of its original $\mathrm{C}$. The coal and shale mixtures lost between 6 and $25 \%$ of their original $\mathrm{C}$. The chemi-thermal method was also compared to two simple thermal oxidation steps $\left(340^{\circ} \mathrm{C}\right.$ for $3 \mathrm{hr}$ and $360^{\circ} \mathrm{C}$ for $\left.4 \mathrm{hr}\right)$ by measuring added geogenic $\mathrm{C}$ in manufactured carbonaceous rock:soil standards. Two different groups of standards were used consisting of added pure coal and added coal and shale at known concentrations. For both groups, simple thermal oxidation at $340^{\circ} \mathrm{C}$ at $3 \mathrm{hr}$ was able to more accurately measure added geogenic $\mathrm{C}$ than the chemi-thermal method. 
This thesis is by no means the work of just one person and would not have been possible without the help and guidance of a number of people who deserve mention here:

First, I would like to thank Dr. Jeff Skousen for his guidance on this project as well my graduate career. I have greatly appreciated not only the work you have done on my behalf to ensure my success as a graduate student, but also your interest in me as a person. You have been an excellent advisor and what I aspire to be as a professional in this field.

To Dr. McDonald and Dr. Sexstone, I owe a great deal of appreciation for trudging through the drafts of this research and offering thorough criticisms and guidance where needed. Your advice has saved me from some serious mistakes more than once. Thank you for serving on my committee.

Next, I would like to thank the other faculty in the Plant and Soil Sciences division who have also taken an interest in me both as an undergraduate and graduate and in this project. A by no means exclusive list and in no particular order would have to include Dr. Pena, Dr. MataPadrino, Dr. Baker and Dr. Bryan in addition to the names listed above. Thank you for being a sounding board for my ideas and steering me into this field by sharing your passion for yours.

I would also like to thank the various other participants in this research who have offered their time and resources so that I would have the ability and a place to conduct this research: Richard Herd and Paul Ziemkiewicz of the WV Water Research Institute; Hobet Mining; Arch Coal; The Upper Potomac River Commission; the Sislers of Hunting Hills and West Virginia DEP.

Finally, this research would be nothing more than thoughts on paper without the help of my fellow graduate students who put in so much of their own time to help me in the field, in the lab and with analyzing my data. Curtis DeLong, John Beck, Mike Harman, Donglin Huang, Sriroop Chaudhuri, Calene Thomas your brief mention here is by no means adequate payment for the help you've given me and I only hope I was able to return at least part of the favor. 


\section{Table of Contents}

Item

Page \#

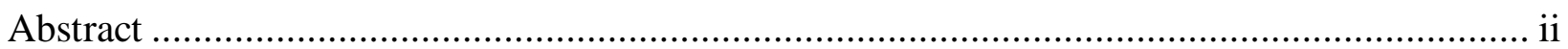

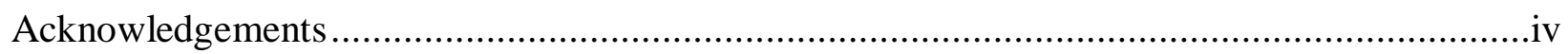

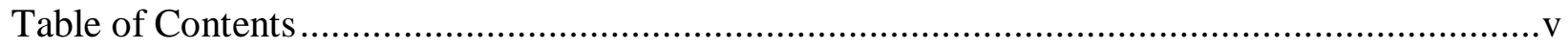

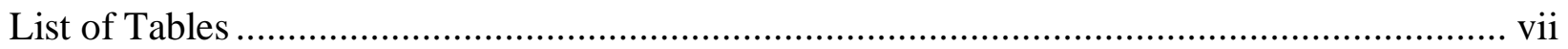

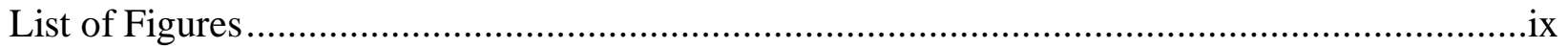

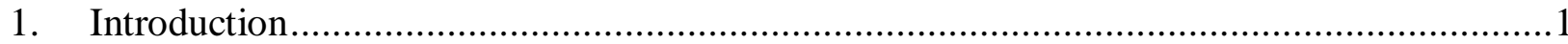

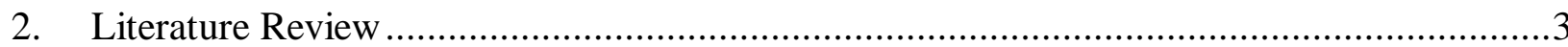

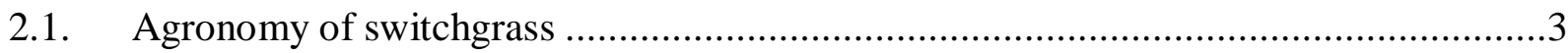

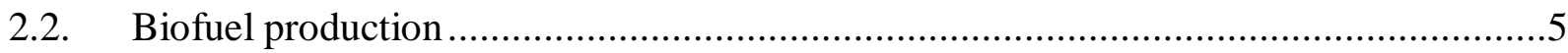

3. Switchgrass Establishment on Newly Reclaimed Land For Biomass Production ................8

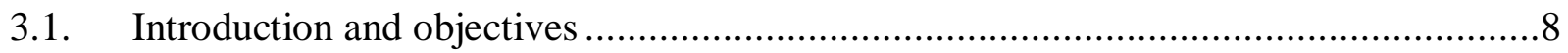

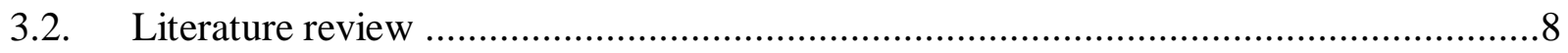

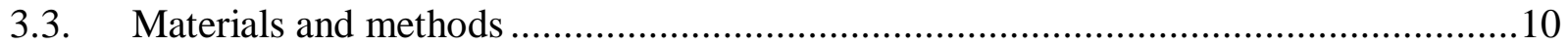

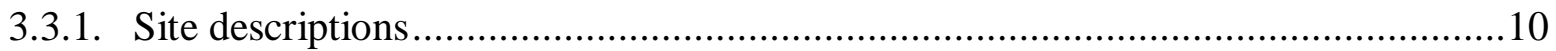

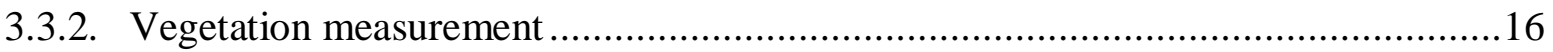

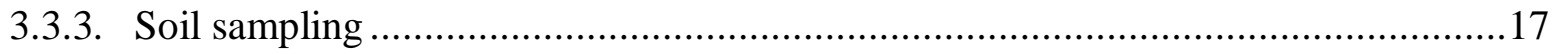

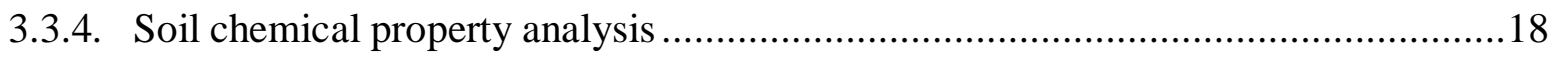

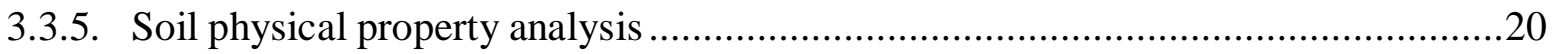

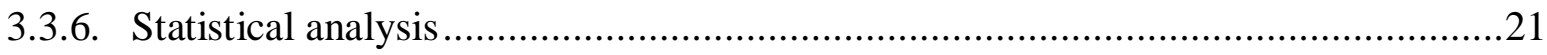

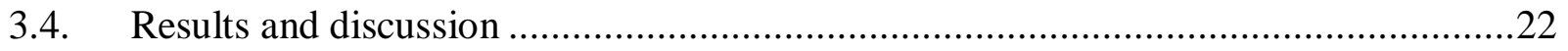

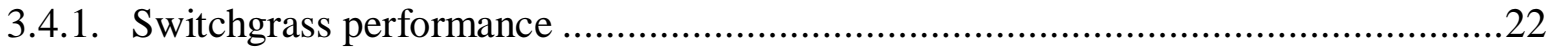

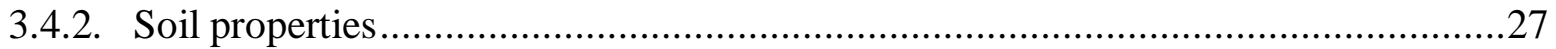

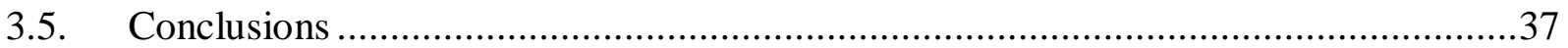


4. Switchgrass C Sequestration on Mined and Unmined Land .......................................39

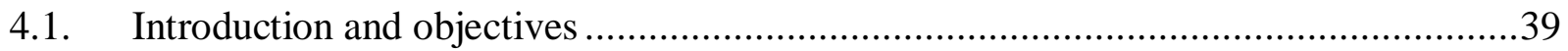

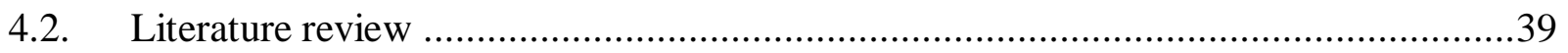

4.3. Materials and methods .............................................................................. 40

4.3.1. Site descriptions............................................................................... 40

4.3.2. Biomass measurement .......................................................................... 41

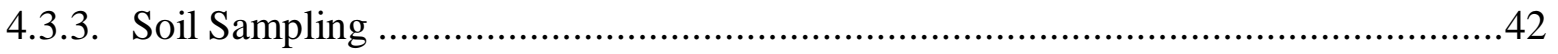

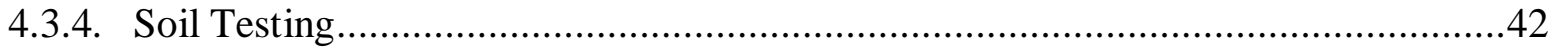

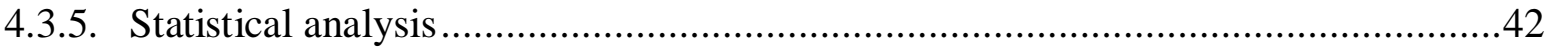

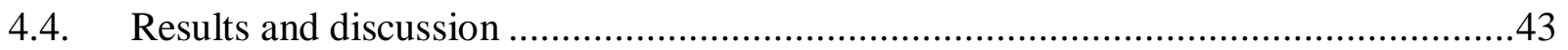

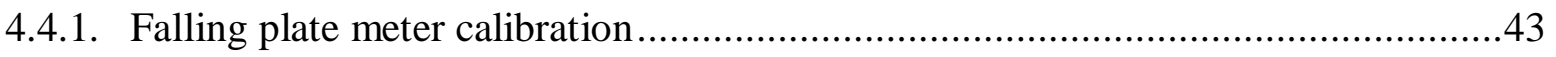

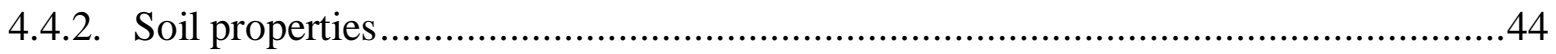

4.4.3. Biomass production ....................................................................... 48

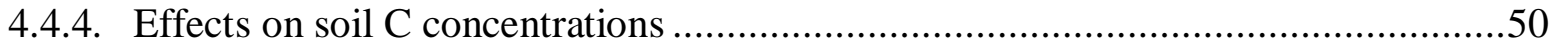

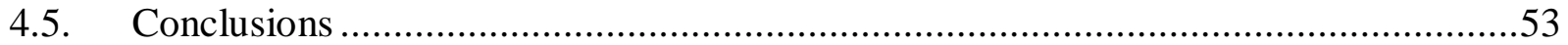

5. Evaluation of the Chemi-Thermal Method to Determine Geogenic C in Mine Soils..........55

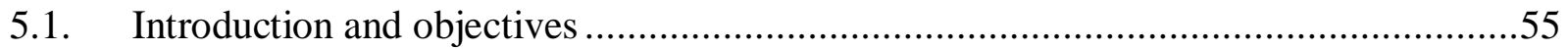

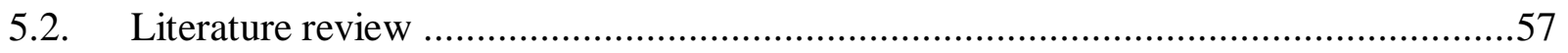

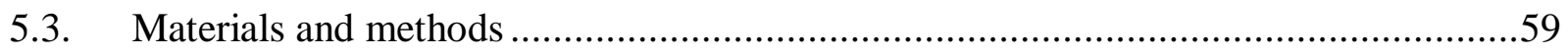

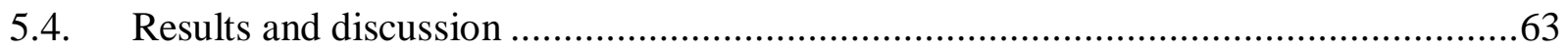

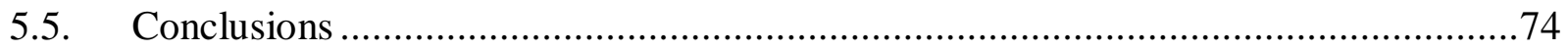

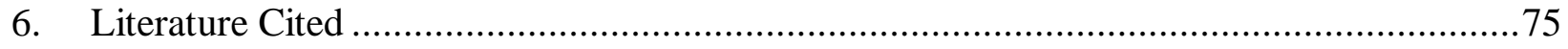




\section{List of Tables}

Table 3-1: Vigor rating scheme for switchgrass performance in 2009.

Table 3-2: ANOVA output for arcsine transformed switchgrass cover measured in 2008. .23

Table 3-3: Arcsine back transformed cover data by variety and mine site in 2008 and 2009 .....23

Table 3-4: ANOVA output for arcsine transformed switchgrass cover measured in 2009. ........24

Table 3-5: ANOVA output for arcsine transformed switchgrass frequency measured in $2008 \ldots . .25$

Table 3-6: Arcsine back transformed switchgrass frequency measured in 2008. ...................25

Table 3-7: ANOVA output for log transformed switchgrass biomass measured in 2009. ..........26

Table 3-8: Log back transformed mean switchgrass biomass by site and variety in 2009 .........26

Table 3-9: Soil nutrients and switchgrass performance by fertilizer treatment.......................27

Table 3-10: Switchgrass vigor by site and variety...................................................22

Table 3-11: Comparison of Mehlich 1 available nutrients among mine sites and between two years of sampling.

Table 3-12: Soil chemical and physical properties among sites for 2008 and 2009.................31

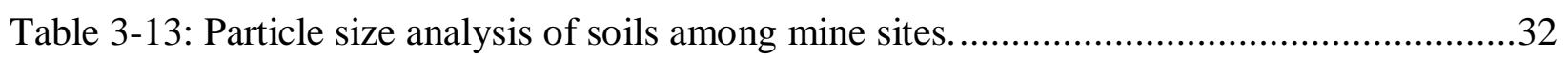

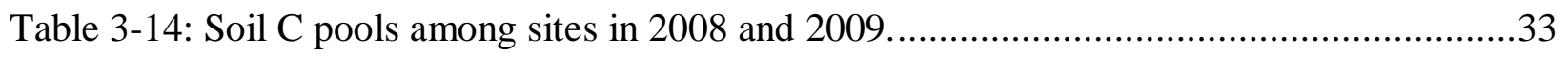

Table 3-15: Range and average inorganic $\mathrm{C}$ as a proportion of total $\mathrm{C}$ for each site. .................34

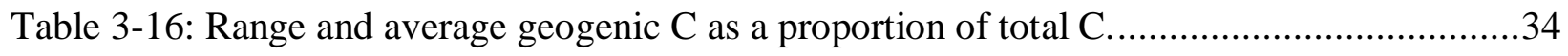

Table 3-17: Significant correlations between soil properties and 2008 switchgrass cover...........35

Table 3-18: Significant correlations between soil properties and 2009 switchgrass cover...........35

Table 3-19: Significant correlations between soil properties and biomass production. ...............36

Table 3-20: Significant correlations between soil properties and 2009 arcsine transformed

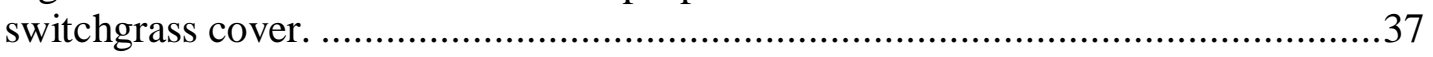

Table 4-1: Mehlich 1 extractable nutrients for mined and unmined soils at $0-15 \mathrm{~cm}$ and $15-30 \mathrm{~cm}$

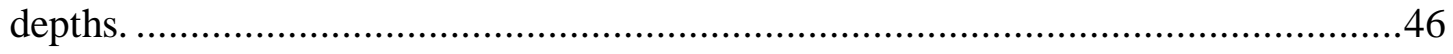


Table 4-2: Soil physical and chemical properties for mined and unmined soils at $0-15 \mathrm{~cm}$ and 15 $30 \mathrm{~cm}$ depths.

Table 4-3: Significant correlations between soil properties and log transformed biomass..........50

Table 4-4: Nontransformed Switchgrass biomass and pedogenic $\mathrm{C}$ at two sampling depths by stand age

Table 4-5: Significant correlations between soil properties and pedogenic C.

Table 5-1: Chemi-thermal method detection of added geogenic $\mathrm{C}$ in manufactured carbonaceous material:soil standards. Group one.

Table 5-2: Chemi-thermal method affect on four carbonaceous materials.

Table 5-3: Chemi-thermal and thermal oxidation method detection of added coal geogenic $\mathrm{C}$ in manufactured carbonaceous material:soil standards.

Table 5-4: Linear regression comparison of the chemi-thermal and thermal oxidation methods used to detect added coal geogenic $\mathrm{C}$ in manufactured carbonaceous material:soil standards.

Table 5-5: Chemi-thermal and thermal oxidation method detection of added coal and shale geogenic $\mathrm{C}$ in manufactured carbonaceous material:soil standards.

Table 5-6: Linear regression comparison of the chemi-thermal and thermal oxidation methods used to detect added coal and shale geogenic $\mathrm{C}$ in manufactured carbonaceous material:soil standards. 


\section{List of Figures}

Figure 3-1: Switchgrass establishment site locations. 10

Figure 3-2: Hobet 21 variety and fertilizer treatment layout. 12

Figure 3-3: Coal-Mac variety and fertilizer treatment layout. 14

Figure 3-4: Hampshire Hill variety layout. .16

Figure 4-1: Falling plate meter calibration for switchgrass biomass at Hunting Hills.

Figure 4-2: Pedogenic $\mathrm{C}$ for two sampling depths by stand age on mined and unmined soils. ....52

Figure 5-1: Chemi-thermal method schematic (Ussiri and Lal, 2008).

Figure 5-2: Chemi-thermal method detection of added geogenic $\mathrm{C}$ in manufactured carbonaceous material:soil standards. Group one. .65

Figure 5-3: C release from the chemi-thermal method on four pure carbonaceous materials. .....66

Figure 5-4: Chemi-thermal and thermal oxidation method detection of added coal geogenic $\mathrm{C}$ in manufactured carbonaceous material: soil standards. .68

Figure 5-5: Chemi-thermal and thermal oxidation method detection of added coal and shale geogenic $\mathrm{C}$ in manufactured carbonaceous material:soil standards. .70

Figure 5-6: No visual change in $\mathrm{C}$ after HF treatment while decanting coal group standards......72

Figure 5-7: Increased $\mathrm{C}$ removal from higher concentrations of coal and shale mixtures observed while decanting coal and shale group standards. 


\section{Introduction}

Surface mining for coal has created many thousands of hectares of reclaimed mine lands across Appalachia. Much of this land has been reclaimed to pasture and hayland post-mining land uses using cool season grasses and legumes. Though these lands are reclaimed to regulatory standards, this particular land use may not be the most productive use of these lands, since few of these sites are actually managed for grazing or forage production after reclamation. Other postmining land uses, such as wildlife habitat or rangeland, are useful but the future economic potential of these lands is often unrealized. However, the production of switchgrass (Panicum virgatum $\mathrm{L}$. ) on these lands for biofuel production and $\mathrm{C}$ sequestration could create new and advantageous post-mining land uses.

This project can be separated into three portions. The first two examine the feasibility and potential of switchgrass as an alternate and potentially economically important post-mining land use. The first part involves the establishment of switchgrass for biomass production on recently mined lands as part of the reclamation process. Mined lands offer the opportunity to increase the land area devoted to biofuel production without subtracting from the area already in food, fiber and feed production. Issues that need to be resolved include establishing the best method of planting switchgrass, the best varieties of switchgrass to utilize in West Virginia and the best management techniques to optimize biomass production. This project seeks to track switchgrass productivity and chemical and physical changes in mine soils as a result of reclamation with switchgrass. Many of these issues have previously been addressed by researchers studying switchgrass on agricultural soils, however there is a definite paucity of information concerning switchgrass management on mined lands. To address these issues, switchgrass was established 
on three different mine sites across the state of West Virginia. Three varieties of switchgrass were chosen and each variety was planted in 0.4 ha plots at each site with three replicates, for a total of 10.8 ha of switchgrass planted in the spring of 2008. These plots were examined for switchgrass establishment success, productivity, soil $\mathrm{C}$ sequestration and other soil chemical and physical properties that may relate to switchgrass performance.

The second portion measures soil organic $\mathrm{C}$ levels in switchgrass stands, and the factors that affect switchgrass performance on mined and natural soils. The site measured in southwestern Pennsylvania had a number of switchgrass plantings which were established for wildlife habitat. The property was mined during the late 1960's, and switchgrass had been planted at various locations on the property since 1991. The effect of switchgrass stand age on soil $\mathrm{C}$ content was determined on both mined and unmined land. Several other soil chemical and physical properties were also measured to determine their effect on soil $\mathrm{C}$ and switchgrass biomass production.

The third part of this research seeks to confirm the ability of the chemi-thermal method (Ussiri and Lal, 2008) to measure C originating from coal and shale in mine soils. Carbon from coal and shale is referred to as geogenic $\mathrm{C}$. The ability to distinguish geogenic $\mathrm{C}$ from soil organic $\mathrm{C}$ is important to any study seeking to measure $\mathrm{C}$ dynamics in mine soils. A small methodological evaluation was performed to determine the chemi-thermal method's effect on coal and shale measured in mine soils. Furthermore, the ability of a simple thermal oxidation procedure to measure geogenic $\mathrm{C}$ was also evaluated against the chemi-thermal method. 
2. Literature Review

\subsection{Agronomy of switchgrass}

Switchgrass (Panicum virgatum L.) is a warm season perennial grass native to North America. Typically recognized as a dominant grass species native to the tall-grass prairie of the Midwestern USA, switchgrass populations exist, or once occurred, from Central America to Southern Canada and from the Atlantic Coast to the Rocky Mountain front in the United States (Hitchcock, 1935). As a managed crop, switchgrass has been traditionally utilized as a warm season forage species (Reid et al., 1988), and more recently as a biomass feedstock for renewable energy (Parrish and Fike, 2005). In addition to biofuel feedstock and forage production, other major uses for switchgrass include conservation plantings to control erosion, sedimentation and nutrient runoff (Nelson et al., 2006). It is also frequently managed as wildlife habitat (Giuliano and Daves, 2002)

In addition to its wide geographical distribution, switchgrass is well adapted to a variety of edaphic conditions. Porter (1966) divided switchgrass populations into two general forms based on the position they favor on the landscape. Lowland varieties are typically found lower on the landscape with more moist soil conditions, while upland varieties are found at higher locations with drier soil conditions. Lowland varieties are typically larger, coarser, and more sensitive to drought stress and can grow to over $3 \mathrm{~m}$ tall (Sanderson et al., 1996). All of the lowland varieties of switchgrass are tetraploid (Hopkins et al., 1996). Upland varieties of switchgrass are typically smaller and more drought resistant. They are either tetraploid, hexaploid or octaploid (Gunter et al., 1996; Hopkins et al., 1996; Hultquist et al., 1996). 
Switchgrass is an efficient user of resources and is well adapted to sites with limited to moderate fertility. Nitrogen requirements for switchgrass vary depending on the specific agroecosystem and more importantly the use for which the crop is managed. Mulkey et al. (2008) suggested that in a mixed species stand similar to the native prairie, no nitrogen would be required for biomass harvesting. Others have also reported little or no response to $\mathrm{N}$ (Staley et al., 1991; Thomason et al., 2004). However, for biomass production Moser and Vogel (1995) suggest applying $100 \mathrm{~kg} \mathrm{~N} \mathrm{ha}^{-1}$ in areas that receive more than $75 \mathrm{~cm}$ rain annually, and $50 \mathrm{~kg} \mathrm{~N}$ $\mathrm{ha}^{-1}$ in areas that receive less than $45 \mathrm{~cm}$ rain. Switchgrass is also a thrifty user of $\mathrm{P}$ and $\mathrm{K}$, and frequently little to no response to fertilizer additions has been seen in many soils (Brejda, 2000). Switchgrass is also tolerant of soils ranging from $\mathrm{pH} 4.5$ to 8.0 although liming acid soils has shown positive yield results (Jung et al., 1988). This ability to perform well on sites with growth limiting conditions is likely due in part to the mutalistic relationship formed between the plant and vesicular-arbuscular mycorrhizae (Clark et al., 1999). The relationship between switchgrass and these fungi have been shown to increase $\mathrm{N}$ and $\mathrm{P}$ uptake and impart a tolerance to drought and acid soils (Parrish and Fike, 2005). Since switchgrass is a $\mathrm{C}_{4}$ grass it is inherently a more efficient user of water, light energy, more tolerant of $\mathrm{N}$ deficiencies, and heat and water stresses. These physiological advantages make switchgrass an attractive choice for biofuel feedstock (Parrish and Fike, 2005) especially on marginal soils where these stresses can be common.

Like many of the warm season grasses, switchgrass is relatively difficult to establish (Henning, 1999). It can often take up to $3 \mathrm{yr}$ for stands to reach full productivity after seeding (Jung et al., 1990). Switchgrass can be established successfully through conventional or no till establishment. Typical seeding rates range from 4-10 $\mathrm{kg} \mathrm{ha}^{-1}$ of pure live seed (Moser and Vogel, 1995; Teel et al., 2003; Vassey et al., 1985; Vogel, 2000; Wolf and Fiske, 1995). Plant densities 
of between 10 and 20 plants $\mathrm{m}^{-2}$ are generally considered successful establishments for biomass plantings (Teel et al., 2003; Vogel, 1987).

Established switchgrass stands generally do not have limiting problems with weeds or pests. During establishment, however, weeds can be a major hindrance (Moser and Vogel, 1995). The triazines have been shown to successfully combat broadleaf and some annual grass weeds in switchgrass (Wolf and Fiske, 1995). Switchgrass is tolerant to atrazine up to rates of $1 \mathrm{~kg} \mathrm{ha}^{-1}$ (Bahler et al., 1984). Unfortunately atrazine is not labeled for use in switchgrass in the vast majority of the country.

\subsection{Biofuel production}

According to a review conducted by Parrish and Fike (2005), before 1970 most research work on switchgrass focused on its role in the native grass ecosystem. Since then it has been studied for a variety of other uses. Much of the work since 1970 focuses on switchgrass managed as a forage crop. It has only been in the last two decades that substantial research has been conducted regarding switchgrass as a bioenergy crop. Beginning in 1984, the U.S. Department of Energy (DOE) began evaluating 36 crops for their potential as a renewable feedstock under the Herbaceous Energy Crops Research Program (HEPC). The HEPC eventually came to the conclusion that switchgrass was the species with the most potential for successful application as a biofuel. By 1991, had DOE decided to focus its research on developing switchgrass into a successful biofuel cropping system at the exclusion of other perennial grass species (Lewandowski et al., 2003; Parrish and Fike, 2005; Wright and Turhollow, 2010).

Since that time researchers have focused on improving and evaluating production methods for switchgrass. A number of trials have shown that switchgrass can be successfully 
grown for biomass (Lemus et al., 2002; Mulkey et al., 2008; Mulkey et al., 2006; Schmer et al., 2006; Tober et al., 2007). Yields vary widely depending on edaphic conditions and geographic location. Schmer et al. (2008) for instance, recorded yields ranging from 5.2 -11.1 Mg ha ${ }^{-1}$ across ten farms in the upper Great Plains states. These yields equated to an average net yield of $60 \mathrm{GJ}$ $\mathrm{ha}^{-1} \mathrm{y}^{-1}$ for switchgrass. They went even further to estimate that cellulosic ethanol from switchgrass could theoretically produce $94 \%$ less greenhouse gasses than an equivalent amount of petroleum-based gasoline. Many authors also point out that switchgrass grown for biofuels is a relatively new crop and that advances in plant breeding and agronomics could substantially increase yields (Lewandowski et al., 2003; Parrish and Fike, 2005; Vogel, 2000; Vogel and Jung, 2001).

Unfortunately, the conversion technologies for transforming switchgrass into a usable energy source are varied and remain in the experimental stage. Switchgrass can be converted to energy rich fuels either through biochemical processes or through chemi-thermal processes. Biochemical processes include anaerobic digestion or fermentation of biomass into ethanol, methanol or other fuels. Ethanol, because it can be blended with petroleum derived gasoline into liquid transportation fuels, remains one of the most attractive fuels for conversion from switchgrass. In the fermentation process to create ethanol, the complex fibers in the cell wall, cellulose and hemicelluloses, are broken down through saccharification into their constituent sugars and then fermented biologically (Datar et al., 2004). The cost of saccharification remains the primary obstacle for economic conversion of cellulosic material into ethanol. Chemi-thermal methods involve gasification and pyrolysis. Gasification is a process that converts biomass directly into $\mathrm{CO}_{2}$ and $\mathrm{H}$ gas (synthesis gas) in a controlled environment at high temperatures. Synthesis gas can be burned directly or further refined into other fuels like methanol. Pyrolysis 
involves burning biomass in the absence of oxygen to produce bio-oil, a product similar to diesel fuel, which can be burned (McKendry, 2002).

Alternatively, switchgrass biomass can also be directly burned in stoves or boilers for space heat or as part of an industrial steam generation process. Switchgrass biomass has been proven to be successfully co-fired in coal fired boilers to offset fossil fuel combustion (Parrish and Fike, 2005; Tillman, 2000). This potential to co-fire switchgrass with coal may become an important end use for biomass in Appalachia given that the region already has a well established infrastructure for coal mining and processing for electricity production. 
3. Switchgrass Establishment on Newly Reclaimed Land For Biomass Production

\subsection{Introduction and objectives}

Growing biomass for bioenergy purposes on mine lands offers the potential for an economically productive post-mining land use. Using these marginal lands for biomass production would allow for an increase in bioenergy production without displacing traditional food or fiber production on agricultural lands while providing alternative energy jobs and income to mining communities. Switchgrass, with its favorable adaptations to poor growing conditions, was seen as a potential bioenergy crop well suited for establishment on reclaimed mine lands.

Accordingly, a research project was conducted to evaluate the feasibility of establishing switchgrass on newly reclaimed mine lands. Field scale plots of switchgrass were planted on three different mine sites typical of West Virginia surface mines in an effort to determine 1) whether switchgrass could be successfully established using techniques and equipment common to mine land reclamation, 2) what varieties of switchgrass perform best on mine lands, and 3) if switchgrass produced enough ground cover and biomass to be utilized as a successful post mining land use.

\subsection{Literature review}

Since switchgrass is adapted to a variety of limiting edaphic conditions, there has been some research done on switchgrass as a tool to reclaim drastically disturbed lands, whether as a monoculture or as part of a mixed species sward. There are number of physical and chemical soil limitations in mine soils that can inhibit plant growth. These can include poor structure and moisture regimes, compaction, restricted rooting, nutrient deficiencies and toxicities, high 
electrical conductivity, and soil acidity (Bendfeldt et al., 2001; Shrestha and Lal, 2006). Switchgrass should be ideally suited for reclamation because of its hardiness and inherent tolerance to a number of these limiting factors. Switchgrass has been used in reclamation studies on roadsides (Skousen and Venable, 2008), strip mines (Rodgers and Anderson, 1995; Skeel and Gibson, 1996), sand and gravel mines (Gaffney and Dickerson, 1987), lignite overburden (Skousen and Call, 1987), and lead and zinc mines (Levy et al., 1999).

No trials have been conducted with switchgrass on mine lands of any type specifically for the purpose of biofuel production. It has been shown that switchgrass can be a successful reclamation species, but research is lacking on whether it can also perform the dual duty of successfully providing adequate amounts of biomass for economic conversion into fuel.

Even without its potential as a biofuel feed stock, switchgrass may still prove a valuable reclamation species because of its ability to sequester C. Carbon sequestration on mine lands offers opportunities to reduce some of the atmospheric $\mathrm{C}$ produced from the combustion of fossil fuels. Shresta and Lal (2006) hypothesized that the United States' 3.2 Mha of mined lands could sequester 1.6 to $3.2 \mathrm{Tg} \mathrm{C} \mathrm{yr}^{-1}$, or enough to offset between 5.8 and $11.7 \mathrm{Tg}$ of $\mathrm{CO}_{2} \mathrm{yr}^{-1}$ emitted by coal combustion activities. The same authors reported that coal emitted $550 \mathrm{Tg} \mathrm{C}$ in 2001 . Akala and Lal (2000) reported soil C pools were higher in lands reclaimed to grass than forest, although they also postulated that $\mathrm{C}$ sequestration potential was higher in forest systems. The same authors in 2001 reported that after 25 years both pasture and forest reclamation returned soil organic C (SOC) pools to amounts similar to the original undisturbed soils (Akala and Lal, 2000). No research has been conducted to specifically measure SOC sequestration trends under switchgrass established on mine lands. 
3.3. Materials and methods

\subsubsection{Site descriptions}

The switchgrass establishment portion of this project took place on three different surface coal mines in West Virginia (Figure 3-1). Each of these mine sites was planted with three varieties of switchgrass replicated three times in 0.4 ha plots. Two of these mines are large mountain top removal mines in southern WV. The third site is a contour mine located in the eastern panhandle of WV.

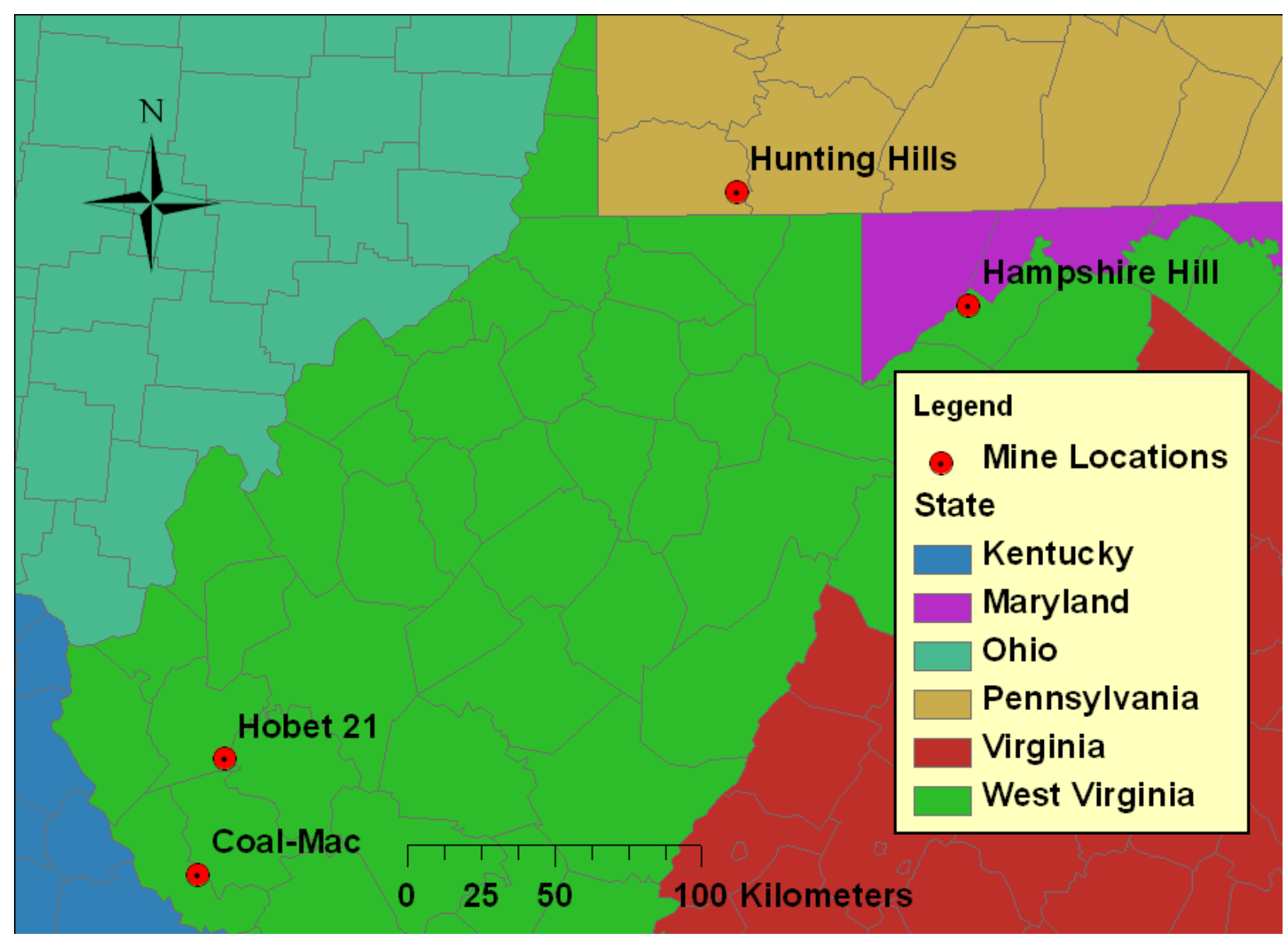

Figure 3-1: Switchgrass establishment site locations. 
Hobet Mining Company, a subsidiary of Magnum Coal, operates the Hobet 21 mine in Boone and Kanawha counties (Figure 3-1). The mine consists of some 4,800 ha of operating and reclaimed mine lands. This mine utilizes a large dragline for overburden removal. The site was reclaimed by rolling out crushed, unweathered rock material over compacted overburden material. The area to be planted was tracked in by a dozer and allowed to sit unvegetated for some time before establishing switchgrass. Before planting, the heavily compacted soil had to be broken up and tilled to ensure proper seed to soil contact. A large earthmoving offset disk harrow was pulled across the site with a large bulldozer to till the soil before planting.

Nine 0.4 ha plots were laid out by hand with a tape measure and marked at the corners with steel T-posts. Each of the three varieties was randomly assigned to one plot until each variety had been replicated three times (Figure 3-2). Planting was conducted on May 28, 2008 using an Earthway Ev-N-Spred hand broadcast spreader. One hundred meter tapes were laid across the plots to use as guides to ensure an even spread of seed. The goal was to seed $4.5 \mathrm{~kg}$ of pure live seed (PLS). Due to the difficulties of planting by hand with different varieties on uneven ground, the amount of seed applied was not always exactly $4.5 \mathrm{~kg}$. After seeding, a light covering of hydromulch was applied over the plots to prevent seed from washing away during rain events and to ensure seed to soil contact. On July 29, 2008, approximately $50 \mathrm{~kg} \mathrm{ha}^{-1}$ of urea was applied to each plot. On July 9, 2009, approximately $200 \mathrm{~kg} \mathrm{ha}^{-1}$ of 19-19-19 fertilizer was applied to one half of each plot. 


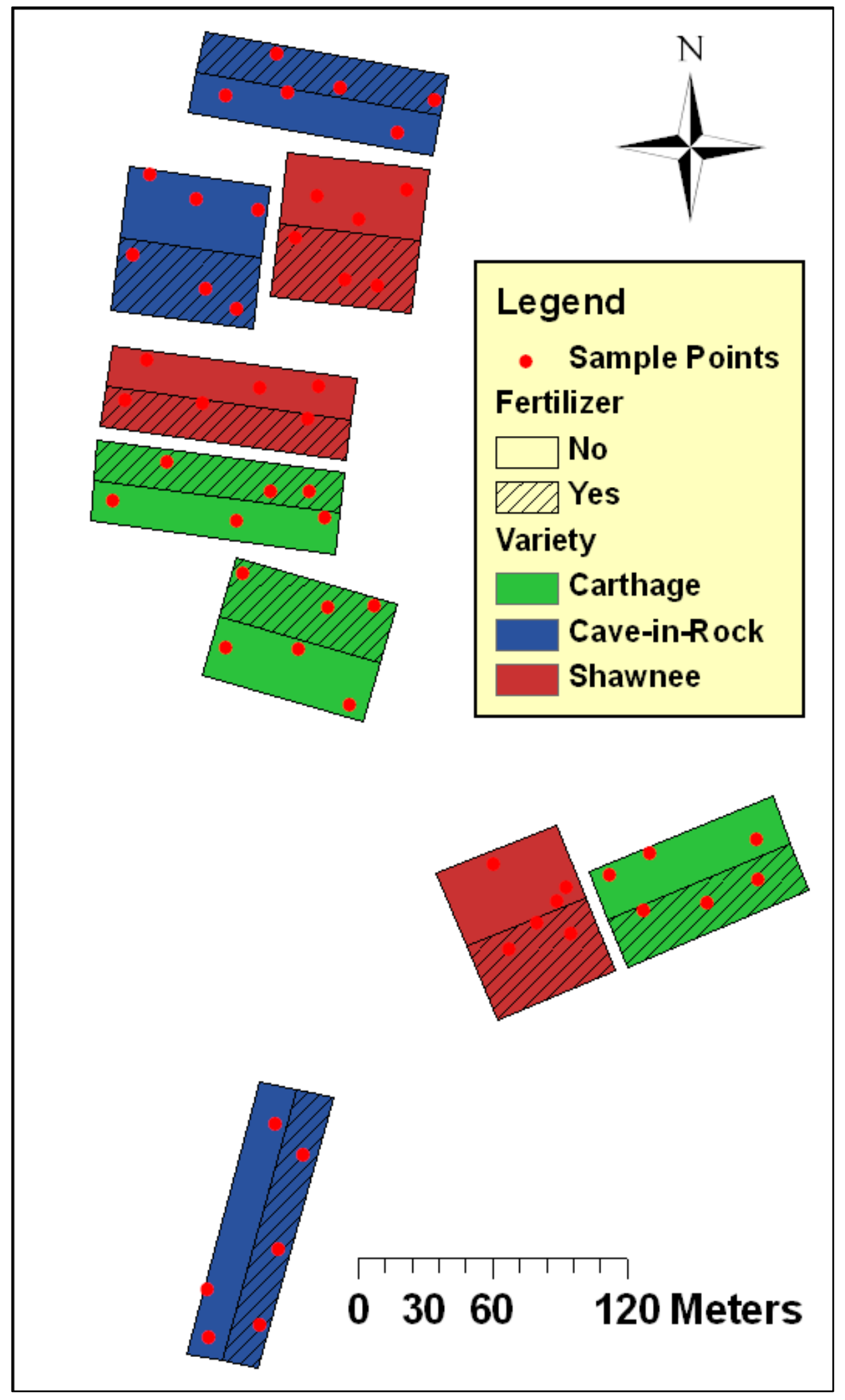

Figure 3-2: Hobet 21 variety and fertilizer treatment layout. 
The Coal-Mac Phoenix Surface \#4 mine is located in Mingo and Logan counties in southern WV (Figure 3-1). The mine is a subsidiary of Arch Coal, Incorporated. It is a large mountain top removal mine that utilizes large power shovels for overburden removal. The site was reclaimed by rolling out soil and weathered rock material over compacted overburden material. Topsoil was tracked in by a bulldozer and then a small agricultural offset disk harrow and tractor were used to prepare the site for planting.

Nine 0.4-ha plots were surveyed by the mining company and plots were marked using steel T-posts. Each of the three varieties was randomly assigned as previously described (Figure 3-3). Seeding at Coal Mac was accomplished with a hydroseeder. For each variety, enough seed for three plots was mixed with $5700 \mathrm{~L}$ of water and a light amount of hydromulch. About onethird (1900 L) of hydroseed mix was spread on each of the three plots assigned to each variety. At the end of the third plot, the truck was thoroughly washed out and the process was repeated until each variety was seeded. Planting was conducted on May 29, 2008. After seeding, a light covering of hydromulch was applied over the plots to protect the seed and promote successful germination. On July 30, 2008 approximately $50 \mathrm{~kg} \mathrm{ha}^{-1}$ of urea was applied to each plot. On July 10, 2009, approximately $200 \mathrm{~kg} \mathrm{ha}^{-1}$ of 19-19-19 fertilizer was applied to one half of each plot. 


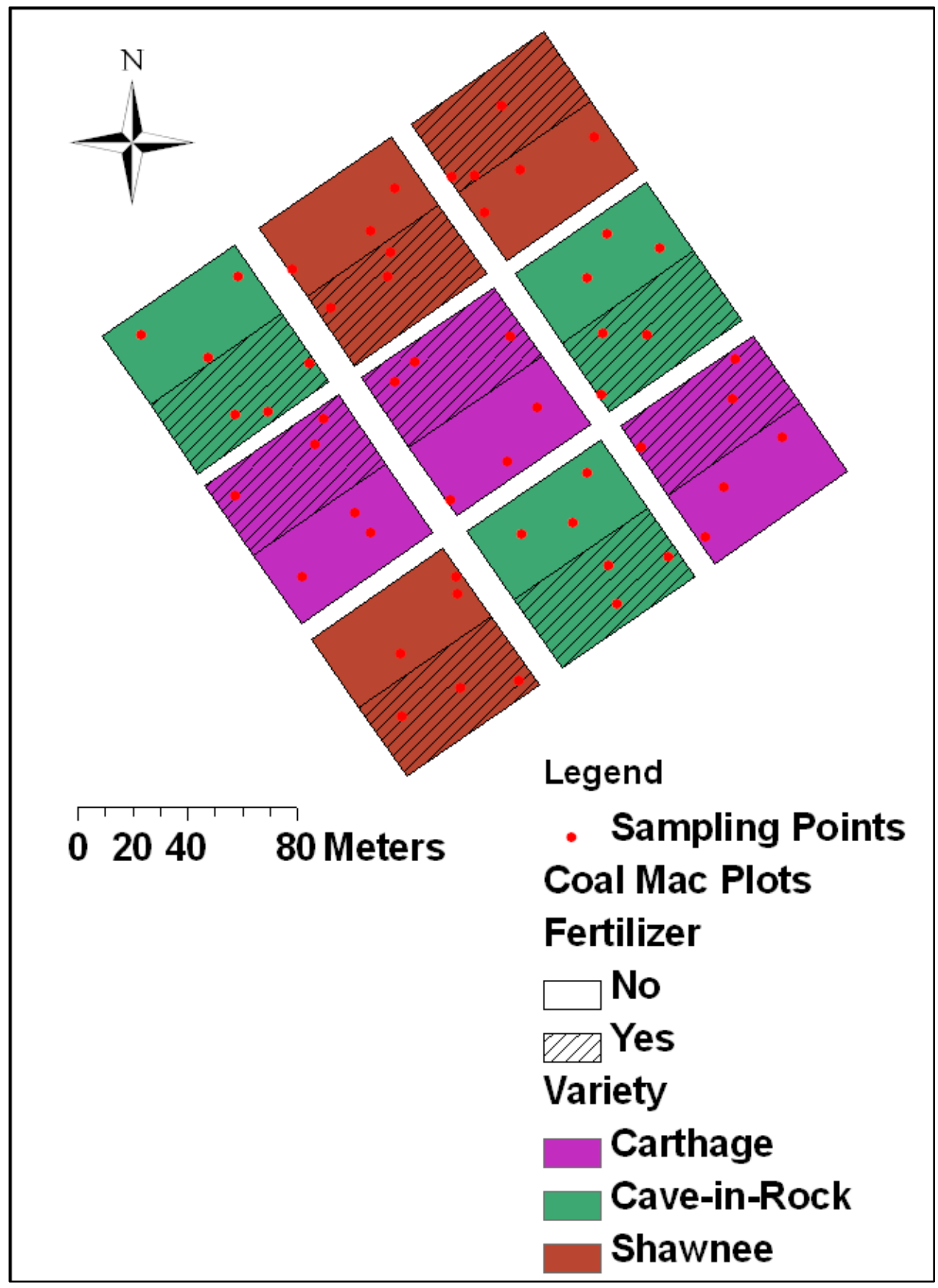

Figure 3-3: Coal-Mac variety and fertilizer treatment layout

The Hampshire Hill Mine is located in Mineral County, West Virginia (Figure 3-1). The property is currently managed by the Upper Potomac River Commission. This site was a small contour mine that utilized smaller mining equipment and trucks. Coal production on the site ceased in April of 1998. Reclamation was completed with rolled out top soil and a top dressing 
of lime-treated sludge from the Westernport, MD municipal wastewater treatment facility which treats industrial waste from the nearby New Page paper mill and sewage from the town of Westernport. Sludge consisting of sewage waste and paper mill pulp was again applied in 2003

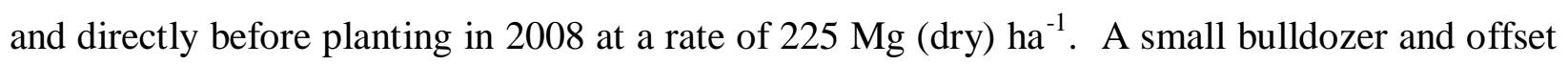
disk harrow were used to prepare the site for planting.

Nine 0.4 ha plots were laid out by hand with a tape measure and marked at the corners with steel T-posts. Each of the three varieties was randomly assigned to one plot until each variety had been replicated three times (Figure 3-4). Planting was conducted on June 13, 2008, using an Earthway Ev-N-Spred hand broadcast spreader. A no-till drill was first tried unsuccessfully due to the overly wet conditions and high moisture holding capacity of the amended mine soil. No fertilizer was applied at this site. Herbicide was applied in June of 2009 to control weeds. Atrazine (2-chloro-4-(ethylamine)-6-(isopropylamine)-s-triazine) was applied in formulation at a rate of $0.75 \mathrm{~L} \mathrm{ha}^{-1}$ active ingredient along with Banvel (3,6-dichloro-o-anisic acid) at a rate of $25 \mathrm{~mL} \mathrm{ha}^{-1}$ active ingredient. 


\section{Legend}

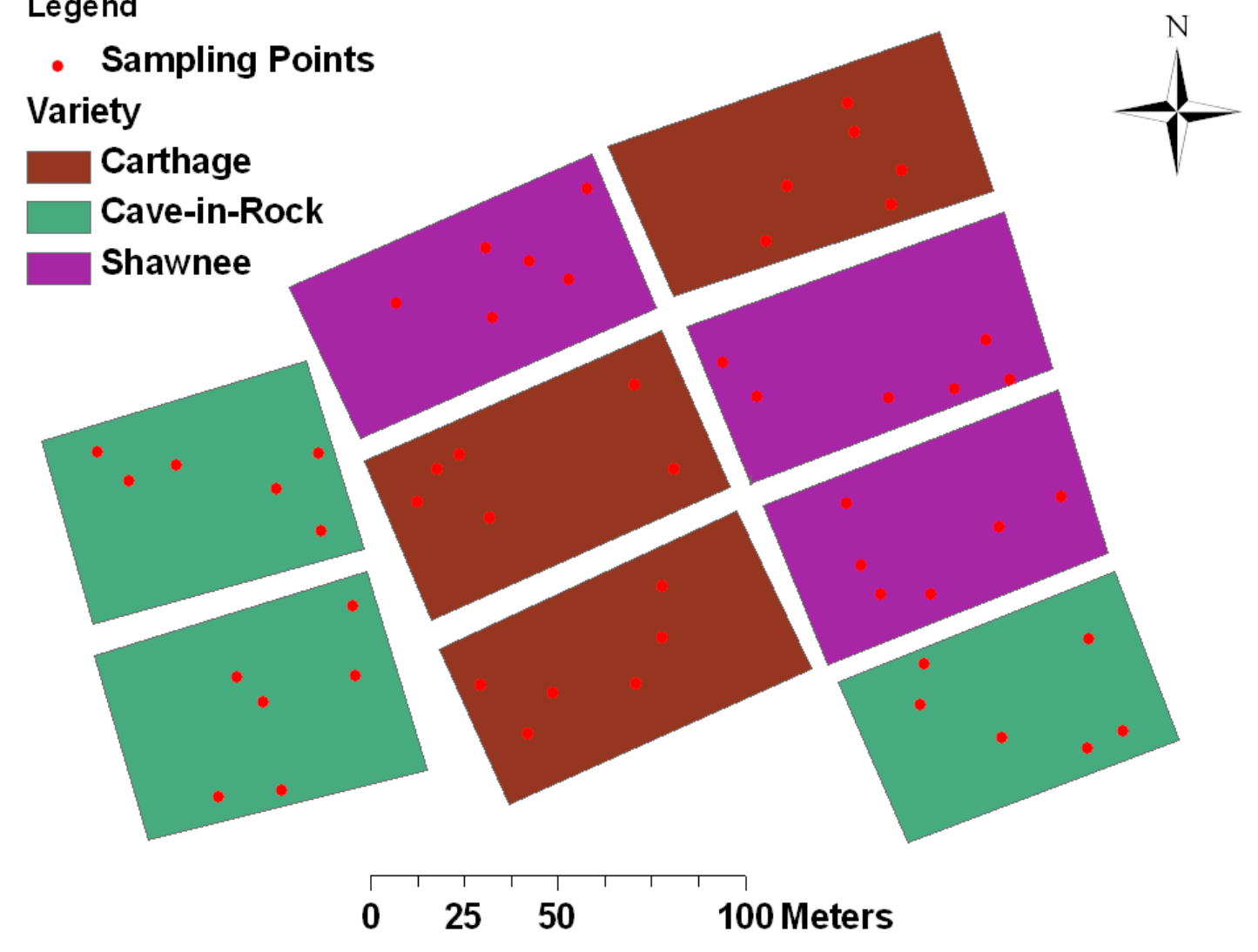

Figure 3-4: Hampshire Hill variety layout.

\subsubsection{Vegetation measurement}

Frequency and percent cover by switchgrass were measured in 2008. It was inappropriate to measure yield in the first year as the switchgrass was not well established. In 2009, biomass and cover were determined. Percent cover was determined by placing four $0.25 \mathrm{~m}^{2}$ quadrats at each randomly placed landscape flag on each plot. Each of the four quadrats placed around the flag were situated at one of the cardinal directions. A visual estimate of the percent of the soil surface covered by switchgrass was recorded. Frequency in 2008 was estimated by calculating what proportion of the 20 quadrats in a field had at least one switchgrass plant. Starting in 2009, 
a stand vigor rating was assigned based on the relative switchgrass performance in a $1 \mathrm{~m}$ radius around soil sampling areas. Table 3-1 describes the vigor rating scheme.

Table 3-1: Vigor rating scheme for switchgrass performance in 2009.

\begin{tabular}{ll}
\hline \multicolumn{1}{c}{ Vigor Rating } & \multicolumn{1}{c}{ Criteria } \\
\hline Very Poor & Seedlings shorter than $5 \mathrm{~cm}$. Most seedlings brown and senesced. Poor cover. \\
Poor & Seedlings between $5-10 \mathrm{~cm}$. Seedlings green but poor cover. \\
Moderate & Grass between $10-20 \mathrm{~cm}$. Better cover. Green plants. \\
Good & Grass greater than $20 \mathrm{~cm}$. Good cover but some gaps. Green plants. \\
Very Good & Grass greater than $20 \mathrm{~cm}$. Nearly $100 \%$ cover. Very best performance. \\
\hline
\end{tabular}

Biomass was determined in 2009 on the plots by randomly placing a $0.21 \mathrm{~m}^{2}$ quadrat within $1 \mathrm{~m}$ around each of six randomly located flags in each of the plots. All the switchgrass in the quadrat was clipped with garden shears and collected. Then it was oven dried at $60^{\circ} \mathrm{C}$ for 48 hr to determine dry weight.

\subsubsection{Soil sampling}

In 2008 at the three switchgrass establishment sites in West Virginia, five points were randomly located in each plot and marked with a landscaping flag. The points were located by placing a landscaping tape on one side of each plot. A random number was generated within the distance on the tape which represented the location of the point on that axis. A second random number was generated that represented a number of paces to be walked perpendicular to the landscaping tape on the opposite axis. One soil sample was randomly taken from a $1 \mathrm{~m}$ radius around each landscaping flag. A total of five soil samples were taken for each 0.4 ha plot, or 45 for each mine site.

Beginning in 2009, plots at the Coal-Mac and Hobet 21 mine sites were split into halves and randomly assigned a fertilizer treatment. Three points were randomly located in each half 
plot using the same method as in 2008. An extra point was placed in each plot at the Hampshire Hill site so that every plot has a total of six randomly placed sampling points for a total of 54 per mine site. Each of these locations was located with a handheld global positioning system (GPSMAP 76+, Garmin Ltd., Olathe, KS.) unit to limit the need for often difficult to locate landscaping flags. Soil samples were taken by extracting a vertical slice of soil and rock $10 \mathrm{~cm}$ deep and placed into a labeled bag. A depth of $10 \mathrm{~cm}$ was used because it is the approximate depth of tillage.

All samples were air dried and sieved with a US \#10 $2 \mathrm{~mm}$ sieve into a fine $(<2 \mathrm{~mm})$ and coarse $(>2 \mathrm{~mm})$ fraction. During sieving any visible roots and plant material were discarded. Both portions were kept for further chemical and physical analysis.

\subsubsection{Soil chemical property analysis}

All chemical analyses were conducted with the fine $(<2 \mathrm{~mm})$ portion of the soil samples unless otherwise noted. To determine $\mathrm{pH}, 5 \mathrm{~g}$ of soil was mixed with $5 \mathrm{~mL}$ of distilled de-ionized (DDI) water. The water and soil were placed on an orbital shaker table and mixed at 180 oscillations per minute for 15 minutes. Then the samples were left to equilibrate for $1 \mathrm{hr}$ before being measured. A Fisher Scientific Accumet XLCO pH electrode calibrated to two points was used to measure each sample.

To determine electrical (EC) conductivity, $5 \mathrm{~g}$ of soil were measured and combined with $10 \mathrm{~mL}$ DDI water. The water and soil were placed on an orbital shaker table for $15 \mathrm{~min}$. Then the samples were allowed to equilibrate for $1 \mathrm{hr}$ before being measured. Either a Fisher Scientific Accumet XLCO EC electrode calibrated to two points or a WTW conductivity meter calibrated to one point were used to measure each sample. 
A Mehlich 1 solution was used to extract available elements found in the soil (Wolf and Beegle, 1995). The Mehlich 1 solution is composed of $0.025 \mathrm{~N} \mathrm{H}_{2} \mathrm{SO}_{4}+0.05 \mathrm{~N} \mathrm{HCL}$. For each sample, $5 \mathrm{~g}$ of soil and $25 \mathrm{~mL}$ of Mehlich 1 solution were combined. The samples were placed on a reciprocating shaker table for $15 \mathrm{~min}$. The samples were passed through a Whatman No. 2 filter paper. The filtrate was then analyzed for aluminum, calcium, iron, magnesium, manganese, phosphorus, potassium, zinc, nickel and copper using a Perkin Elmer inductively coupled plasma emission spectrometer (DV 2100 ICP-OES, Perkin Elmer, Norwalk, CT).

Total soil C was determined using a LECO TruSpec CHN elemental analyzer (LECO Corp., St Joseph, MI). Soil was ground with a porcelain mortar and pestle to pass a US \#60 sieve $(<0.250 \mathrm{~mm})$. Each sample was weighed into foil cups and combusted at $950^{\circ} \mathrm{C}$ to determine total $\mathrm{C}$. The amount of $\mathrm{C}$ in the form of evolved $\mathrm{CO}_{2}$ was measured using an infrared gas spectrometer. Combustion at this temperature liberates all forms of $\mathrm{C}$ present in the sample including $\mathrm{C}$ from inorganic carbonates and organic $\mathrm{C}$ from carbonaceous rock material like coal and shale.

To accurately describe soil organic $\mathrm{C}$ in mine soils it is necessary to account for $\mathrm{C}$ from carbonate and carbonaceous rock sources. The method of Ussiri and Lal (2008) was used to distinguish between soil organic (pedogenic) $\mathrm{C}$, carbonate (inorganic) $\mathrm{C}$ and carbonaceous rock (geogenic) C. A detailed description of this method is provided in section 5. This method uses several chemical reagents to remove inorganic and pedogenic $\mathrm{C}$ and relies on the resistance to thermal oxidation of coal material at $340^{\circ} \mathrm{C}$ to determine geogenic C. A subset of 37 randomly chosen samples per site was used to determine $\mathrm{C}$ pools. 


\subsubsection{Soil physical property analysis}

Fines, or soil that passes through a US \# $102 \mathrm{~mm}$ sieve, were measured on a percent weight basis. Before sieving, each soil sample was weighed. Then the $>2 \mathrm{~mm}$ (coarse) fraction of the sample was washed, allowed to air dry and then weighed. Percent fines were determined by taking the total weight of the sample subtracted by the weight of the coarse material divided by the total weight.

Soil particle size analysis was determined using the pipette method (Gee and Bauder, 1986) on a subset of 16 samples per establishment site. Approximately $10 \mathrm{~g}$ of soil were measured into $300 \mathrm{~mL}$ fleakers. To remove organic matter, hydrogen peroxide (30\% wt.) was added to cover the soil. The reaction was allowed to proceed until bubbling stopped. Then, another $10 \mathrm{~mL}$ of peroxide were added and the reaction was allowed to proceed until bubbling stopped. Samples were then oven dried at $105^{\circ} \mathrm{C}$ overnight. Samples were removed, allowed to cool and weighed to determine starting soil weight. Sodium hexametaphosphate (HMP) at a concentration of $50 \mathrm{~g} \mathrm{~L}^{-1}$ was used as a dispersion agent. The fleakers were then filled with exactly $10 \mathrm{~mL}$ HMP solution and approximately $150 \mathrm{~mL}$ DDI water. The samples were shaken for $3 \mathrm{hr}$ on a reciprocating shaker table. Samples were then washed from the fleakers into $1 \mathrm{~L}$ volumetric settling columns and filled to capacity with DDI water. Samples were stirred vigorously and then permitted to settle a specific amount of time based on the temperature of a 5 $\mathrm{g} \mathrm{L}^{-1}$ HMP blank column. The amount of settling time is based on the constant settling rate of soil particles based on size and temperature as predicted by Stoke's Law. After settling, $25 \mathrm{~mL}$ of suspended clay particles were pipetted into a tared beaker and allowed to dry at $105^{\circ} \mathrm{C}$ overnight. The remaining soil was emptied from the settling column into a US \# $270(.053 \mathrm{~mm})$ sieve to 
collect sand sized particles. Sand was then wet sieved with tap water and placed back into tared fleakers to dry overnight with the clay samples. Clay and sand sized particles were then weighed and determined on a percent total soil basis. Silt sized particles are determined as the difference between sand and clay particles and total soil weight.

\subsubsection{Statistical analysis}

The effect of switchgrass variety and mine site on cover, frequency and biomass was determined using a $3 \times 3$ factorial analysis of variance to test for significant differences and interactions. This analysis was performed separately on cover for 2008 and 2009 since it was measured both years. ANOVA was then used to compare cover between both years grouped by each mine site. Model effects were first fitted using untransformed data and the residuals were examined for normality. Cover, frequency and biomass were all non-normal distributions which could confound attempts at statistical comparison using ANOVA so comparisons were made with transformed data. Cover and frequency were transformed using the arcsine of the square root of each observation to make the data more normal. Biomass distribution was made more normal by first adding 0.5 to each observation to ensure non-zero values and then taking the log of each observation. Normal quantile plots as well as kurtosis and skewness were used to judge if transforming observations was justified. Mean values were determined by back transforming accordingly.

The effect of fertilizer application on soil test $\mathrm{P}$ and $\mathrm{K}$, biomass production and cover was examined within Coal-Mac and Hobet 21 separately using an ANOVA comparison of fertilized and unfertilized plots using transformed data for biomass and cover. The effects of variety and mine on vigor were examined using Pearson's Chi-squared test. 
Soil properties were compared among sites using ANOVA. Additionally the change in these properties from 2008 to 2009 was examined using an ANOVA comparison by year grouped by each mine. Soil properties were then correlated with transformed switchgrass cover and biomass production using a simple linear regression separately for each soil property. Samples that had no switchgrass performance were excluded from this correlation. All analyses were performed with SAS Institute JMP 8.0.1 software. Significance was determined at $p<0.05$ and Tukey's Honestly Significant Difference test was used post hoc to determine separation of means.

\subsection{Results and discussion}

\subsubsection{Switchgrass performance}

Cover was measured in 2008 as the percentage of soil canopy made up of switchgrass. During this first year, switchgrass cover ranged from only 1.5 to $3.0 \%$. Before fitting the model data was transformed by taking the arcsine of the square root of each observation. Mine site and variety were significant model parameters (Table 3-2). Comparisons of variety were performed within each mine site with the transformed data. The only significant difference was at Hampshire Hill where Cave-in-Rock was significantly better than the other two varieties (Table 3-3). At this site, Cave-in-Rock had an average cover of 3.3\% while Carthage and Shawnee were $1.6 \%$ and $1.9 \%$ respectively. It is unclear why Cave-in-Rock had the best cover, and it should be noted that only a relatively small absolute difference in cover (less than $2 \%$ ) was noticed. 
Table 3-2: ANOVA output for arcsine transformed switchgrass cover measured in 2008.

\begin{tabular}{lcccc}
\hline \multicolumn{1}{c}{ Source } & $\begin{array}{c}\text { Degrees of } \\
\text { Freedom }\end{array}$ & $\begin{array}{c}\text { Sum of } \\
\text { Squares }\end{array}$ & F Ratio & Prob $>$ F \\
\hline Variety & 2 & 0.0187 & 6.94 & $0.0014^{*}$ \\
Mine & 2 & 0.0085 & 3.15 & $0.0465^{*}$ \\
Variety*Mine & 4 & 0.0120 & 2.23 & 0.0696 \\
\hline
\end{tabular}

* Denotes statistical significance at $\mathrm{p}=0.05$ with arcsine transformed data.

Table 3-3: Arcsine back transformed cover data by variety and mine site in 2008 and 2009

\begin{tabular}{cccc}
\hline Mine Site & Variety & Hobet 21 & Coal-Mac \\
\hline \multirow{3}{*}{ Hobet 21} & & 2008 & 2009 \\
\cline { 2 - 4 } & Carthage & $----------\%$ & --------- \\
& Cave-in-Rock & 2.2 & 7.3 \\
& Shawnee & $1.8 \dagger$ & 4.8 \\
Coal-Mac & Carthage & $1.8 \dagger$ & 11.5 \\
& Cave-in-Rock & $1.7 \dagger$ & 17 \\
& Shawnee & $1.5 \dagger$ & 35 \\
Hampshire Hill & Carthage & $1.5 \mathrm{a} \dagger$ & 19 \\
& Cave-in-Rock & $3.0 \mathrm{~b} \dagger$ & 99 \\
& Shawnee & $1.7 \mathrm{a} \dagger$ & 100 \\
& & & 99 \\
\hline
\end{tabular}

* Different letters denote statistical significance among varieties within individual sites and years at $\mathrm{p}=0.05$ with arcsine transformed data

$\dagger$ Denotes significant differences between years for each variety at each site at $\mathrm{p}=0.05$ with arcsine transformed data.

Only mine site yielded a significant effect when using the same design to examine switchgrass cover in 2009 by site and variety (Table 3-4). Since there was no significant interaction among site and variety, it is appropriate to evaluate the main effect of site. Hampshire Hill had significantly more cover than Coal-Mac, which were both significantly larger than Hobet 21. There was no significant difference among any of the varieties within sites measured in 2009 (Table 3-3). The increase in cover from 2008 to 2009 was significant for each variety at Coal Mac and Hampshire Hill and only significant for Shawnee at Hobet 21 (Table 3-3). Cover 
as a whole was much more variable at Coal-Mac and Hobet 21 than at Hampshire Hill with some areas performing much better than others.

Table 3-4: ANOVA output for arcsine transformed switchgrass cover measured in 2009.

\begin{tabular}{lcccc}
\hline \multicolumn{1}{c}{ Source } & $\begin{array}{c}\text { Degrees of } \\
\text { Freedom }\end{array}$ & $\begin{array}{c}\text { Sum of } \\
\text { Squares }\end{array}$ & F Ratio & Prob $>$ F \\
\hline Variety & 2 & 450 & 0.51 & 0.601 \\
Mine & 2 & 215915 & 245 & $<0.001 *$ \\
Variety*Mine & 4 & 2511 & 1.43 & 0.228 \\
\hline * Denotes statistical significance at $\mathrm{p}=0.05$ with arcsine transformed data.
\end{tabular}

Frequency was also measured on a plot by plot basis in 2008 as the number of quadrats that had at least one switchgrass plant. Values for arcsine back transformed frequency were quite high (between 85 to $99 \%$ ), meaning that switchgrass plants were distributed quite evenly over the plots. Only the main effect of site was significant when comparing arcsine transformed data (Table 3-5). Hampshire hill had a lower average frequency for all three varieties (Table 3-6). The low frequency at Hampshire Hill was most likely due to unevenness during the actual seeding process and not due necessarily to any edaphic or switchgrass related characteristics. The planting was done with one person and no planting aids were used to ensure an even coverage. This is supported by the fact that Hobet and Coal-Mac had nearly identical frequency and that some strips of vegetation were visibly present at Hampshire Hill as the result of uneven coverage from the spinner spreader. There were no differences in frequency among variety at any of the sites. Schmer et al. (2006) suggested that stand frequencies of $40 \%$ or greater would be adequate for switchgrass biomass production in the year after planting. Of course, frequency could decrease from seedlings dying, but it appears that initial germination from broadcasting or hydroseeding could produce a viable stand for biomass production. 
Table 3-5: ANOVA output for arcsine transformed switchgrass frequency measured in 2008.

\begin{tabular}{lcccc}
\hline \multicolumn{1}{c}{ Source } & $\begin{array}{c}\text { Degrees of } \\
\text { Freedom }\end{array}$ & $\begin{array}{c}\text { Sum of } \\
\text { Squares }\end{array}$ & F Ratio & Prob $>$ F \\
\hline Variety & 2 & 0.0087 & 0.130 & 0.8793 \\
Mine & 2 & 0.3574 & 5.336 & $0.0152^{*}$ \\
Variety*Mine & 4 & 0.0163 & 0.122 & 0.9728 \\
\hline
\end{tabular}

* Denotes statistical significance at $\mathrm{p}=0.05$ with arcsine transformed data.

Table 3-6: Arcsine back transformed switchgrass frequency measured in 2008.

\begin{tabular}{lccc}
\hline & Hobet 21 a & Coal Mac a & Hampshire Hill b \\
\hline Carthage & $99 \%$ & $99 \%$ & $91 \%$ \\
Cave-in-Rock & $99 \%$ & $99 \%$ & $92 \%$ \\
Shawnee & $99 \%$ & $99 \%$ & $85 \%$ \\
\hline$*$ Mines not covered by the same letter are significantly different at $\mathrm{p}=0.05$ with \\
arcsine transformed data.
\end{tabular}

Only mine site was significant when comparing log transformed biomass production (Table 3-7). The average biomass production at Hampshire Hill was $4501 \mathrm{~kg} \mathrm{ha}^{-1}$ compared to $784 \mathrm{~kg} \mathrm{ha}^{-1}$ and $217 \mathrm{~kg} \mathrm{ha}^{-1}$ at Coal Mac and Hobet, respectively (Table 3-8). Hampshire Hill outperformed both Coal-Mac and Hobet 21. When compared within each site individually, only Hampshire Hill showed a significant difference with Cave-in-Rock being the best performer of the three varieties. The much larger biomass production at Hampshire Hill can be at least partly contributed to the application of municipal biosolids which probably increased water holding capacity and nutrient supply. Rodgers and Anderson (1995) also reported increased switchgrass growth with increased biosolids application on mine lands. 
Table 3-7: ANOVA output for log transformed switchgrass biomass measured in 2009.

\begin{tabular}{lcccc}
\hline Source & $\begin{array}{c}\text { Degrees of } \\
\text { Freedom }\end{array}$ & $\begin{array}{c}\text { Sum of } \\
\text { Squares }\end{array}$ & F Ratio & Prob $>$ F \\
\hline Variety & 2 & 1.306 & 0.532 & 0.5886 \\
Mine & 2 & 182.379 & 74.306 & $<0.0001$ \\
Variety*Mine & 4 & 2.948 & 0.600 & 0.6629 \\
\hline
\end{tabular}

* Denotes statistical significance at $\mathrm{p}=0.05$ with $\log$ transformed data.

Table 3-8: Log back transformed mean switchgrass biomass by site and variety in 2009.

\begin{tabular}{|c|c|c|c|}
\hline & Coal Mac & Hobet 21 & Hampshire Hill \\
\hline & \multicolumn{3}{|c|}{-------------------------------kg ha' } \\
\hline Carthage & 54 & 11 & 3219 \\
\hline Cave-In-Rock & 52 & 6 & 6248 \\
\hline Shawnee & 99 & 21 & 3079 \\
\hline
\end{tabular}

* Different letters in columns denote statistical significance at $\mathrm{p}=0.05$.

In 2009, approximately $200 \mathrm{~kg} \mathrm{ha}^{-1}$ of 19-19-19 fertilizer was applied to one-half of each plot at Hobet 21 and Coal-Mac to examine the effect of fertilizer application on soil properties and switchgrass production (Table 3-9). At Hobet 21, both cover and biomass significantly improved with fertilization while soil test $\mathrm{P}$ and $\mathrm{K}$ did not change. At Coal-Mac, soil test $\mathrm{P}$ and $\mathrm{K}$ levels increased significantly while cover and biomass showed slight increases. None of the other Mehlich 1 available nutrients showed a significant difference between fertilized and unfertilized areas suggesting that the differences were in fact due to fertilizer application. One explanation for this difference in soil test values and biomass between sites is that the applied nutrients remained in the soil causing no increase in biomass at Coal-Mac with the opposite being true at Hobet 21 . 
Table 3-9: Soil nutrients and switchgrass performance by fertilizer treatment.

\begin{tabular}{llcc}
\hline & & Fertilized & Unfertilized \\
\hline Hobet 21 & $\mathrm{K}\left(\mathrm{mg} \mathrm{kg}^{-1}\right)$ & 46.9 & 44.2 \\
& $\mathrm{P}\left(\mathrm{mg} \mathrm{kg}^{-1}\right)$ & 32.8 & 32.9 \\
& Biomass $\left(\mathrm{kg} \mathrm{h}^{-1}\right)$ & $31^{*}$ & 1.6 \\
& Cover $(\%)$ & $14^{*}$ & 3.1 \\
Coal-Mac & $\mathrm{K}\left(\mathrm{mg} \mathrm{kg}^{-1}\right)$ & $52.2^{*}$ & 40.7 \\
& $\mathrm{P}\left(\mathrm{mg} \mathrm{kg}^{-1}\right)$ & $15.9^{*}$ & 12.1 \\
& Biomass $\left(\mathrm{kg} \mathrm{ha}^{-1}\right)$ & 72 & 60 \\
& Cover $(\%)$ & 23 & 24 \\
\hline * Denotes statistical significance between fertilizer treatments at $\mathrm{p}=0.05$. \\
Biomass and cover are compared using log and arcsine transformed data \\
respectively.
\end{tabular}

Vigor, an objective measurement of the switchgrass plant's relative performance, was also measured in 2009. Pearson's Chi-squared test showed a significant correlation among mine site and average vigor (ChiSq=0.05). The Hobet site averaged a vigor rating between very poor and poor while the Coal-Mac site averaged between poor and moderate. At Hampshire Hill, all samples rated very good (Table 3-10). There was no significant statistical correlation in vigor among any of the varieties or between fertilization treatments at any of the mine sites.

Table 3-10: Switchgrass vigor by site and variety.

\begin{tabular}{llll}
\hline Variety & Hobet 21 & Coal Mac & Hampshire Hill \\
\hline Cave-In-Rock & Very Poor to Poor & Poor to Moderate & Very Good \\
Shawnee & Very Poor to Poor & Poor to Moderate & Very Good \\
Carthage & Very Poor to Poor & Poor to Moderate & Very Good \\
\hline
\end{tabular}

\subsubsection{Soil properties}

In addition to vegetation measurements, a number of soil physical and chemical properties were also measured in an effort to determine if any edaphic conditions might significantly influence switchgrass growth. 
In 2008, there were a variety of differences among the available nutrients in the three sites (Table 3-11). Only the micronutrient $\mathrm{Cu}$ showed no significant difference among sites. Notable is the large increase in basic cations present at Hampshire Hill from the heavy application of lime treated municipal waste. It is speculated that the attendant drop in available $\mathrm{P}$ is from the formation of Ca-P mineral precipitates. Fe and $\mathrm{P}$ were high at Hobet, with lower values at Coal-Mac and even lower amounts at Hampshire Hill. This may be the result of the differences in amounts of unweathered spoil in the soil material among those three sites. 
Table 3-11: Comparison of Mehlich 1 available nutrients among mine sites and between two years of sampling.

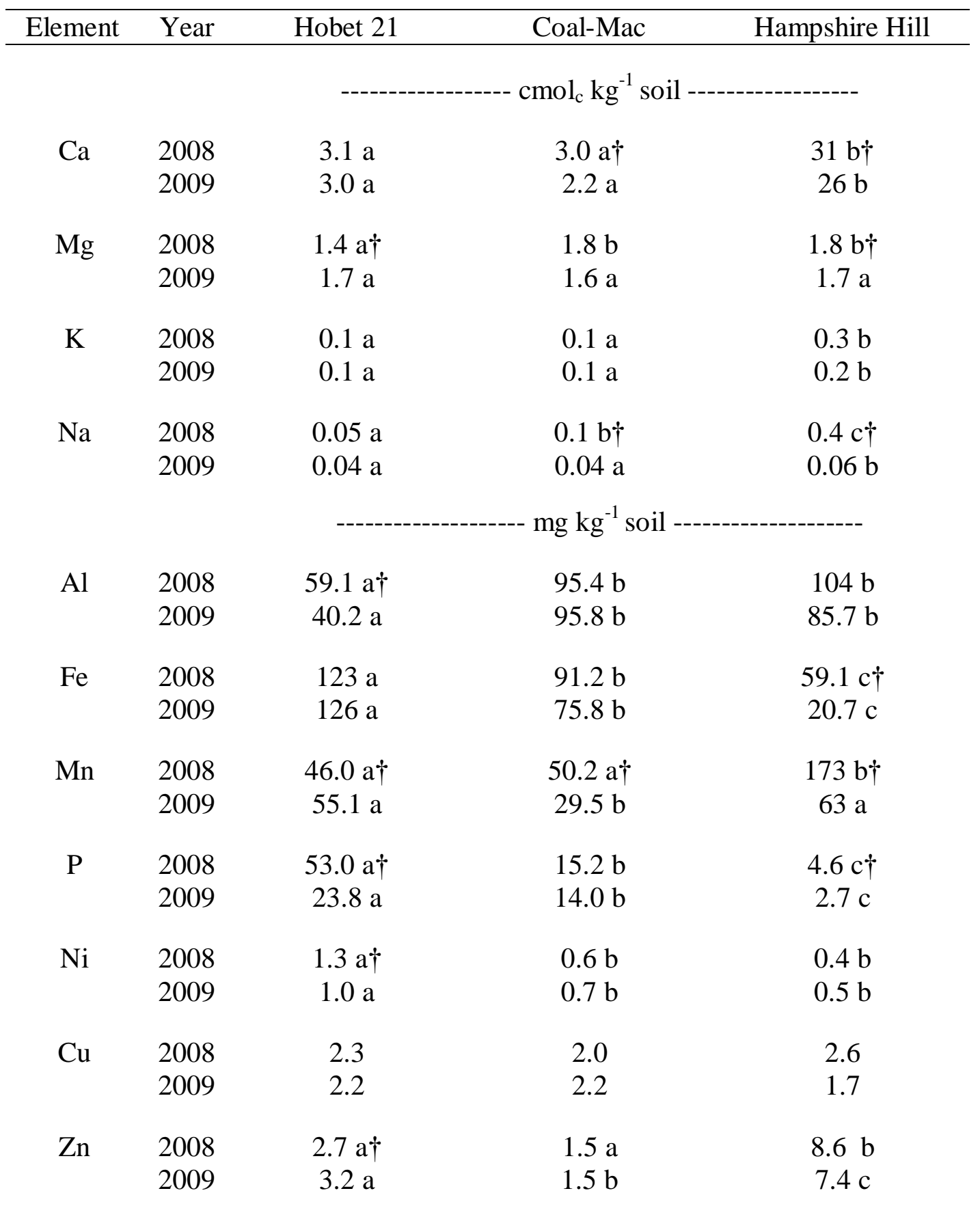

* Values within rows not covered by the same letter are statistically significant at $\mathrm{p}=0.05$.

$\dagger$ Denotes statistical difference between years for each element at each site at $\mathrm{p}=0.05$ 
Similarly, in 2009 there was a difference between nutrients among at least one pair of the three mine sites in all of the nutrients except for $\mathrm{Cu}$ and $\mathrm{Mg}$. Once again Hampshire Hill showed much higher levels of basic cations, although those levels decreased from 2008 to 2009 (Table 3-11). Hampshire Hill had six nutrients which decreased including $\mathrm{Fe}, \mathrm{Mn}, \mathrm{Mg}, \mathrm{Ca}, \mathrm{Na}$, and $\mathrm{P}$. At Coal Mac, only Mn, Ca, and Na decreased. At Hobet 21, Al, Mg, P and Ni decreased while $\mathrm{Mn}$ and $\mathrm{Zn}$ increased. This suggests that either weathering was causing a release of these two elements or that the significant increase in $\mathrm{pH}$ from 2008 to 2009 was changing their availability. The general decrease in most nutrients at all three sites can probably be attributed to leaching, the formation of unavailable complexes, incorporation into biomass, or a combination of the three.

Soil pH, electrical conductivity, percent fines and total $\mathrm{C}$ were also measured in 2008 and 2009. Soil $\mathrm{pH}$ in 2008 for all three sites was within the range for which switchgrass is adapted and should perform well (Table 3-12). Coal Mac had the lowest $\mathrm{pH}$ at 6.1, probably because a greater proportion of the mine soil material was made up of natural soil compared to Hobet. Hobet's relatively high $\mathrm{pH}$ was probably because the mine soil material was made up of mostly unweathered sandstone containing carbonates. Hampshire Hill's high $\mathrm{pH}$ was likely due to the large amounts of lime used to treat the municipal waste that was applied at this site. Electrical conductivity, total $\mathrm{C}$ and percent fines were much higher at Hampshire Hill than the other two sites as the result of reclaiming with a higher proportion of natural topsoil and from the application of municipal waste. 
Table 3-12: Soil chemical and physical properties among sites for 2008 and 2009.

\begin{tabular}{lcccc}
\hline Property & Year & Hobet 21 & Coal-Mac & Hampshire Hill \\
\hline \multirow{2}{*}{ pH } & 2008 & $7.3 \mathrm{a} \dagger$ & $6.1 \mathrm{~b}$ & $7.2 \mathrm{a} \dagger$ \\
& 2009 & $7.9 \mathrm{a}$ & $6.3 \mathrm{c}$ & $7.3 \mathrm{~b}$ \\
$\mathrm{EC}\left(\mu \mathrm{S} \mathrm{cm}^{-1}\right)$ & 2008 & $187 \mathrm{a} \dagger$ & $258 \mathrm{a} \dagger$ & $1245 \mathrm{~b} \dagger$ \\
& 2009 & $69 \mathrm{a}$ & $55 \mathrm{a}$ & $382 \mathrm{~b}$ \\
& & & & \\
Total C $(\%)$ & 2008 & $1.6 \mathrm{a}$ & $2.1 \mathrm{~b}$ & $7.7 \mathrm{c}$ \\
& 2009 & $1.4 \mathrm{a}$ & $1.9 \mathrm{a}$ & $7.1 \mathrm{~b}$ \\
\multirow{2}{*}{ Fines $(\%)$} & 2008 & $56 \mathrm{a}$ & $55 \mathrm{a}$ & $77 \mathrm{~b} \dagger$ \\
& 2009 & $58 \mathrm{a}$ & $60 \mathrm{a} \uparrow$ & $81 \mathrm{~b}$
\end{tabular}

* Values within rows not covered by the same letter are statistically significant at $\mathrm{p}=0.05$.

$\uparrow$ Denotes statistical difference between years for each property at each site at $\mathrm{p}=0.05$.

From 2008 to 2009, pH rose significantly at the Hobet 21 site from 7.3 to 7.9 (Table 3-12). Electrical conductivity fell at each site suggesting that some leaching and removal of ions was taking place. Percent fines also increased significantly at Coal-Mac and Hampshire Hill suggesting that some breakdown of overburden material into finer material was taking place. Total C decreased slightly at all three sites, but the change was not statistically significant.

Hobet 21 and Coal-Mac had nearly identical textures and are both classified as sandy loams (Table 3-13). Hampshire Hill was more finer textured and was classified as a loam. Hampshire Hill had statistically higher amounts of clay and silt and less sand. 
Table 3-13: Particle size analysis of soils among mine sites.

\begin{tabular}{lccc}
\hline & Hobet 21 & Coal-Mac & Hampshire Hill \\
\hline & ------- & 0 \\
Sand & $64 \mathrm{a}$ & $62 \mathrm{a}$ & $40 \mathrm{~b}$ \\
Silt & $28 \mathrm{a}$ & $28 \mathrm{a}$ & $38 \mathrm{~b}$ \\
Clay & $8 \mathrm{a}$ & $10 \mathrm{a}$ & $22 \mathrm{~b}$ \\
\hline * Values within rows that are not covered by the same letter are statistically \\
significant at $\mathrm{p}=0.05$.
\end{tabular}

Hampshire Hill had statistically higher amounts of inorganic (carbonate) C, pedogenic (soil organic) C, and geogenic (coal and shale) C (Table 3-14). This was expected considering this site was reclaimed with lime. The mining operation at Hampshire Hill was much smaller than the other two mines and the coal seam was much closer to the soil surface which led to a larger amount of coal and organic shale mixed in the spoil used for reclamation. Although not statistically significant, small differences also appeared between Coal-Mac and Hobet 21. CoalMac was reclaimed with more original topsoil and so had a smaller amount of inorganic $\mathrm{C}$ and a slightly higher amount of pedogenic $\mathrm{C}$. 
Table 3-14: Soil C pools among sites in 2008 and 2009.

\begin{tabular}{lcccc}
\hline Element & Year & Hobet 21 & Coal-Mac & Hampshire Hill \\
\hline \multirow{2}{*}{ Inorganic C } & 2008 & $0.12 \mathrm{a}$ & $0.049 \mathrm{a}$ & $0.64 \mathrm{~b}$ \\
& 2009 & $0.11 \mathrm{a}$ & $0.051 \mathrm{a}$ & $0.74 \mathrm{~b}$ \\
& & & & \\
Pedogenic C & 2008 & $1.07 \mathrm{a}$ & $1.41 \mathrm{a}$ & $6.26 \mathrm{~b} \dagger$ \\
& 2009 & $0.78 \mathrm{a}$ & $1.17 \mathrm{a}$ & $4.77 \mathrm{~b}$ \\
Geogenic C & 2008 & $0.44 \mathrm{a}$ & $0.66 \mathrm{a}$ & $1.52 \mathrm{~b}$ \\
& 2009 & $0.68 \mathrm{a}$ & $0.70 \mathrm{a}$ & $1.96 \mathrm{~b}$ \\
\hline
\end{tabular}

* Values within rows not covered by the same letter are statistically significant at $\mathrm{p}=0.05$.

$\dagger$ Denotes statistical difference between years for each $\mathrm{C}$ pool at each site at $\mathrm{p}=0.05$.

The same trends that occurred among sites in 2008 occurred in 2009 with Hampshire Hill having larger amounts of all three types of C (Table 3-14). When comparing 2008 to 2009, only one significant difference occurred with Hampshire Hill showing a smaller amount of pedogenic C. This may mean that the large amount of organic C applied as bio-solids rapidly oxidized over the course of the year perhaps as the result of microbial degradation. This is supported by the fact that total $\mathrm{C}$ also decreased slightly at Hampshire Hill. It should be mentioned, however, that although not statistically significant, there was a concurrent increase in inorganic $\mathrm{C}$ and geogenic C measured in 2009. Any errors related to these two concentrations would compound the error associated with pedogenic $\mathrm{C}$ concentration since it is determined by difference.

Inorganic $\mathrm{C}$ and geogenic $\mathrm{C}$ both represented a substantial proportion of the total $\mathrm{C}$ found in soils at all three sites (Table 3-15 and Table 3-16). Inorganic $\mathrm{C}$ represented anywhere from 0 to $36 \%$ of total C. Geogenic C represented anywhere from 10 to $79 \%$ of total C. Both these C pools must be accurately accounted for in order to properly assess the $\mathrm{C}$ dynamics in mine soils and not overestimate soil organic $\mathrm{C}$. The proportion of inorganic $\mathrm{C}$ was lowest at Coal-Mac. 
Despite having the highest concentration of geogenic $\mathrm{C}$ in the soil, the Hampshire Hill mine actually had the lowest proportion in relation to total C.

Table 3-15: Range and average inorganic $\mathrm{C}$ as a proportion of total $\mathrm{C}$ for each site.

\begin{tabular}{lccc}
\hline & Hobet 21 & Coal Mac & Hampshire Hill \\
\hline High & 36 & 9 & 23 \\
Low & 0 & 0 & 0 \\
Mean & $8 \mathrm{a}$ & $3 \mathrm{~b}$ & $8 \mathrm{a}$ \\
\hline * Mean values not covered by the same letter are statistically significant at \\
$\mathrm{p}=0.05$.
\end{tabular}

Table 3-16: Range and average geogenic $\mathrm{C}$ as a proportion of total $\mathrm{C}$.

\begin{tabular}{lccc}
\hline & Hobet 21 & Coal Mac & Hampshire Hill \\
\hline & ---------- & $\%$ of total C --------------- \\
High & 63 & 79 & 60 \\
Low & 21 & 18 & 10 \\
Mean & $38 \mathrm{a}$ & $34 \mathrm{a}$ & $24 \mathrm{~b}$ \\
\hline
\end{tabular}

* Means values not covered by the same letter are statistically significant at $\mathrm{p}=0.05$.

Since soil properties and switchgrass performance data were collected from the same sampling points, an attempt was made to distinguish what soil properties may have influenced switchgrass cover and biomass. Few meaningful trends were seen within each mine site. For 2008, cover was positively correlated to geogenic C and pedogenic C at Coal-Mac (Table 3-17). Increased pedogenic (soil organic) $\mathrm{C}$ would improve plant growth by improving nutrient availability and plant available water holding capacity. It is unclear if geogenic $\mathrm{C}$ specifically had any positive impact on plant growth because it was also strongly correlated with pedogenic $\mathrm{C}$, meaning that where the mine soil had more pedogenic $\mathrm{C}$ there was also an attendant increase in geogenic C contamination. Several other factors not listed in Table 3-17 were also weakly correlated $\left(\mathrm{R}^{2}<30\right)$ with cover at Hobet 21 and Coal-Mac. However, speculating on relationships 
with such low correlation coefficients is difficult since so little of the variation in cover is related to those soil properties.

Table 3-17: Significant correlations between soil properties and 2008 switchgrass cover.

\begin{tabular}{cc}
\hline Soil Property & Correlation Coefficient \\
\hline Coal-Mac & \\
Geogenic C & 0.55 \\
Pedogenic C & 0.55 \\
\hline * All properties listed are significant at $\mathrm{p}=0.05$ for \\
the $\mathrm{R}^{2}$ values shown for arcsine transformed cover.
\end{tabular}

For cover measured in 2009, particle size distribution and geogenic $\mathrm{C}$ had a significant correlation with percent cover at the Hobet 21 site (Table 3-18). The negative correlation for sand and positive correlation for silt and clay strongly suggests that cover was improved with finer textured soils. It is likely that the finer textured soils were able to provide more plant available water to the plants. Again there were other poorly correlated factors not listed because of the inability to account for a significant portion of the variance in cover.

Table 3-18: Significant correlations between soil properties and 2009 switchgrass cover.

\begin{tabular}{lc}
\hline \multicolumn{1}{c}{ Soil Property } & Correlation Coefficient \\
\hline Hobet 21 & \\
Geogenic C & 0.39 \\
Sand & -0.55 \\
Silt & 0.49 \\
Clay & 0.69 \\
\hline
\end{tabular}

* All properties listed are significant at $\mathrm{p}=0.05$ for the $\mathrm{R}^{2}$ values shown arcsine transformed cover.

Some soil properties were also correlated to biomass production (Table 3-19). At Hobet 21, texture was correlated to biomass in the same way that it was correlated to cover in 2009 suggesting that finer textured soils were benefiting plant growth. At Coal-Mac, geogenic $\mathrm{C}$ was negatively correlated to biomass. It is unclear what mechanism could cause this. One explanation 
might be that geogenic $\mathrm{C}$ is correlated to some other soil property not measured that is limiting to switchgrass growth. At Hampshire Hill, the proportion of silt was found to be negatively correlated to switchgrass biomass. This site was observed to have poor drainage so it could be possible that excessively silty areas were limiting switchgrass performance.

Table 3-19: Significant correlations between soil properties and biomass production.

\begin{tabular}{lc}
\hline \multicolumn{1}{c}{ Soil Property } & Correlation Coefficient \\
\hline Hobet 21 & -0.50 \\
Sand & 0.45 \\
Silt & 0.60 \\
Clay & \\
Coal-Mac & -0.46 \\
Geogenic C & -0.37 \\
Hampshire Hill & \\
Silt & \\
\hline * All properties listed are significant at $\mathrm{p}=0.05$ for \\
the $\mathrm{R}^{2}$ values shown log transformed biomass.
\end{tabular}

Since there were relatively few correlations to switchgrass biomass within sites, it was decided to compare soil properties across all three sites. Table 3-20 lists some of the most strongly correlated variables. Other variables that were weakly correlated $\left(\mathrm{R}^{2}<0.30\right)$ were not shown and include $\mathrm{Al}, \mathrm{Fe}, \mathrm{Mn}, \mathrm{Ca}, \mathrm{Zn}, \mathrm{Na}, \mathrm{P}, \mathrm{Ni}$, geogenic $\mathrm{C}$, and inorganic $\mathrm{C}$. It is important to note that the properties listed in Table 3-20 are also the properties that made the Hampshire Hill site statistically different from the other two sites. Based on this, it is logical to assume that some of the properties that made Hampshire Hill different also improved switchgrass performance. Pedogenic $\mathrm{C}$ and finer textured soils obviously benefit plant growth on mine soils by improving water holding capacity and cation exchange capacity. It is unclear if the nutrients and EC listed in Table 3-20 actually favored switchgrass performance or if they were artifacts of the high lime application and biosolids amendment at Hampshire Hill. 
Table 3-20: Significant correlations between soil properties and 2009 arcsine transformed switchgrass cover.

\begin{tabular}{lc}
\hline Soil Property & Correlation Coefficient \\
\hline K & 0.36 \\
EC & 0.46 \\
\% Fines & 0.31 \\
\% Total C & 0.47 \\
\% Pedogenic C & 0.39 \\
\% Sand & -0.50 \\
\% Silt & 0.40 \\
\% Clay & 0.46 \\
\hline
\end{tabular}

* All properties listed are significant at $\mathrm{p}=0.05$ for the $\mathrm{R}^{2}$ values shown for $\log$ transformed biomass.

\subsection{Conclusions}

The establishment portion of this project confirmed that switchgrass can be planted as the initial reclamation species on mine soils using methods already commonly employed in reclamation. Cover and frequency data directly after planting indicated a successful stand distribution with an even coverage of germinated plants. Cover and biomass from the second year after establishment showed that mine soil properties play an important role in determining switchgrass performance. Fertilizer application was shown to have only limited effects on the two sites where it was applied suggesting that nutrient deficiency may not be the most important factor related to switchgrass performance on these soils. High biomass and cover were observed on the Hampshire Hill site which had finer textured soils and more pedogenic organic C. Both of these factors increased this site's ability to provide plant available nutrients and water. Accordingly, efforts should be made to create finer textured soils with higher amounts of organic $\mathrm{C}$ during the reclamation process to promote the successful establishment and performance of switchgrass. Soil amendment with biosolids was a successful method of achieving this goal. Given the relatively low performance of switchgrass at Hobet 21 and Coal-Mac, it is apparent 
that while established switchgrass is tolerant to many poor soil conditions, its small seeded nature limits its ability to establish successfully and vigorously on rocky, nutrient-deficient mine soils. Switchgrass may not be an appropriate initial reclamation species when adequate soil cover and biomass production are expected within one growing season of planting. There is, however, the potential for switchgrass to become an economically important post mining land use on mine soils already established with ground cover that are currently under utilized. Research in this area is beginning. 
4. Switchgrass C Sequestration on Mined and Unmined Land

\subsection{Introduction and objectives}

Using switchgrass can reduce anthropogenic $\mathrm{C}$ emissions in two ways. If utilized as a fuel source, $\mathrm{C}$ emissions from switchgrass combustion are offset by atmospheric $\mathrm{C}$ recently incorporated into biomass though photosynthesis. Switchgrass can also distribute atmospheric C into soil organic matter through litter deposition and root senescence. In C degraded soils, like those that are affected by drastic disturbances, deforestation or intensive agriculture, establishing perennial grasses like switchgrass can increase soil $\mathrm{C}$ and subsequently act as a net reduction of atmospheric C.

Carbon dynamics under perennial bioenergy crops are less well understood when compared to other land uses like agriculture. The objective of this study was to determine how the age of a switchgrass stand affects soil $\mathrm{C}$ concentrations on mined and unmined soils located in the same area and with the same management history. Switchgrass productivity and other soil properties were also measured to determine their effect on soil $\mathrm{C}$ concentrations.

\subsection{Literature review}

In addition to being well suited for management as a biofuel feedstock, there is also a great deal of interest in switchgrass due to its ability to sequester atmospheric $\mathrm{C}$ in soil organic matter (SOM). As plants return their litter into the soil and roots turn over, some of the $\mathrm{C}$ in those materials becomes inaccessible to soil microbes and is highly resistant towards mineralization. This soil organic carbon (SOC) becomes stable and is considered sequestered in the soil (Shrestha and Lal, 2006). 
When perennial species are planted on degraded lands, they can increase SOC levels due to their high biomass production and deep roots (Lemus and Lal, 2005; Ma et al., 2000; Tolbert et al., 2002). Frank et al. (2004) concluded that switchgrass sequestered $10 \mathrm{Mg} \mathrm{C}^{-1} \mathrm{yr}^{-1}$ when measured $0.9 \mathrm{~m}$ deep in a frigid mollisol. Of course, these figures depend on SOC levels present before the establishment of switchgrass and are a factor of several conditions including edaphic characteristics, management practices, climate and plant growth (Bransby, 1998). Positive C storage can only occur when these perennial biomass crops replace row crops or are planted on otherwise C denuded lands (Lemus and Lal, 2005). Regardless of the amount of C stored underground, biofuels can still be a positive tool in reducing greenhouse gases because $\mathrm{C}$ emitted during consumption of the fuel is recently removed from the atmosphere during photosynthesis (Kort et al., 1998).

\subsection{Materials and methods}

\subsubsection{Site descriptions}

Hunting Hills is a 300 ha, privately owned, outdoor recreation area and game habitat located near Diliner in southwestern Pennsylvania. Portions of the property were contour mined in the late 1960's by the Twilight Mining Company. Some of the mined property was planted with white pine (Pinus strobus L.) at the time of reclamation while the rest was reclaimed to grassland. At the time of the first switchgrass establishment in 1991, the majority of the mined land that was not planted in white pine was dominated by broom sedge (Andropogon virginicus L.). The areas that were not mined were either previously in mixed hardwood forest, row crop production or cool season grassland. Today the site consists of many different aged switchgrass stands (from 1991 to 2008) on both mined and unmined lands. 
The switchgrass on the property is managed specifically for wildlife habitat for popular game bird species like bobwhite quail (Colinus virginianus) and pheasant (Phasianus colchicus). Fields are generally burned each spring before green up. Occasionally some stands have been harvested in July for hay and allowed to regrow for the winter. Lime has been spread periodically. Stands were established either conventionally with a prepared seedbed and a drill or broadcast spreader, or with a no-till drill into an herbicide-killed sod. To determine the effect of switchgrass on soil $\mathrm{C}$ sequestration, samples were taken across different aged stands on both reclaimed and non mined lands and from a depth of $0-15 \mathrm{~cm}$ and $15-30 \mathrm{~cm}$.

\subsubsection{Biomass measurement}

Biomass was determined on the Hunting Hills plots using a falling plate meter (Rayburn and Lozier, 2003). A $0.21 \mathrm{~m}^{2}$ acrylic plate with a hole in the center was placed on and completely supported by the forage to be measured. A meter stick was then placed in the center hole to measure the plate's height above the ground. This process was done once every $3 \mathrm{~m}$ across a transect in each of the plots to be measured. Each height was averaged across the transect to form a plot average. To calibrate the height of the plate to actual biomass production, 20 random 0.21

$\mathrm{m}^{2}$ areas across the research site were measured for height and then the same area was clipped. The forage was returned to the lab and was oven dried at $60^{\circ} \mathrm{C}$ for $48 \mathrm{hr}$ to determine dry weight. This was done to account for the specific stand density, variety and maturity of this location that would not be represented in other generic calibration equations. 


\subsubsection{Soil Sampling}

For the $\mathrm{C}$ sequestration site at Hunting Hills, fields of interest were located with a GPS unit (GPSMAP 76+, Garmin Ltd., Olathe, KS.) and then divided roughly into halves. Soil cores were taken along a transect in each portion of the field at a distance of about $5 \mathrm{~m}$ apart with a standard soil probe. Each core was divided into a $0-15 \mathrm{~cm}$ portion and a $15-30 \mathrm{~cm}$ portion. The soil cores for each half of a field were bulked according to depth and then treated as one composite sample.

All samples were air dried and sieved with a US \#10 $2 \mathrm{~mm}$ sieve into a fine $(<2 \mathrm{~mm})$ and coarse $(>2 \mathrm{~mm})$ fraction. During sieving any visible roots and plant material were discarded. Both portions were kept for further chemical and physical analyses.

\subsubsection{Soil Testing}

All soil chemical and physical properties were determined in the same manner as described in sections 3.3.4 and 3.3.5. Soil C pools were determined on all of the mined samples and particle size analysis was not determined.

\subsubsection{Statistical analysis}

At Hunting Hills, analysis of variance was also used to compare soil parameters and biomass production between mining treatments and then by soil depths. Biomass, total $\mathrm{C}$ and pedogenic $\mathrm{C}$ were compared between mined and unmined soils and the residuals were examined for normality. Total $\mathrm{C}$ and pedogenic $\mathrm{C}$ residuals appeared normally distributed using skewness, kurtosis and normal quantile plots as estimators. Biomass data was log transformed to make the 
residuals more normal. Biomass data used to develop the falling plate meter calibration were not transformed. Soil properties and stand age were then correlated with switchgrass biomass and soil C. Linear regression was also used to calibrate falling plate meter height to switchgrass biomass. All analyses were performed with SAS Institute JMP 8.0.1 software. Significance was determined at $\mathrm{p}<0.05$.

\subsection{Results and discussion}

\subsubsection{Falling plate meter calibration}

A regression equation was developed for the Hunting Hills site to calibrate the height of falling plate meter to switchgrass biomass. The regression equation developed was statistically significant at $\mathrm{p}<0.05$ and had an $\mathrm{R}^{2}=0.65$ (Figure 4-1). A plot of the residuals showed that the regression equation was less accurate in predicting forage weight as plate height increased. The majority of the data from the actual field plots $(>75 \%)$ fell within the range of plate heights that had low residuals. A calibration equation specific to this site was generated to account for this site's specific stand variety, maturity and density. These are factors which may affect plate height but would not be represented in other generalized calibration equations for other swards, even though these other equations may have stronger $\mathrm{R}^{2}$ values. 


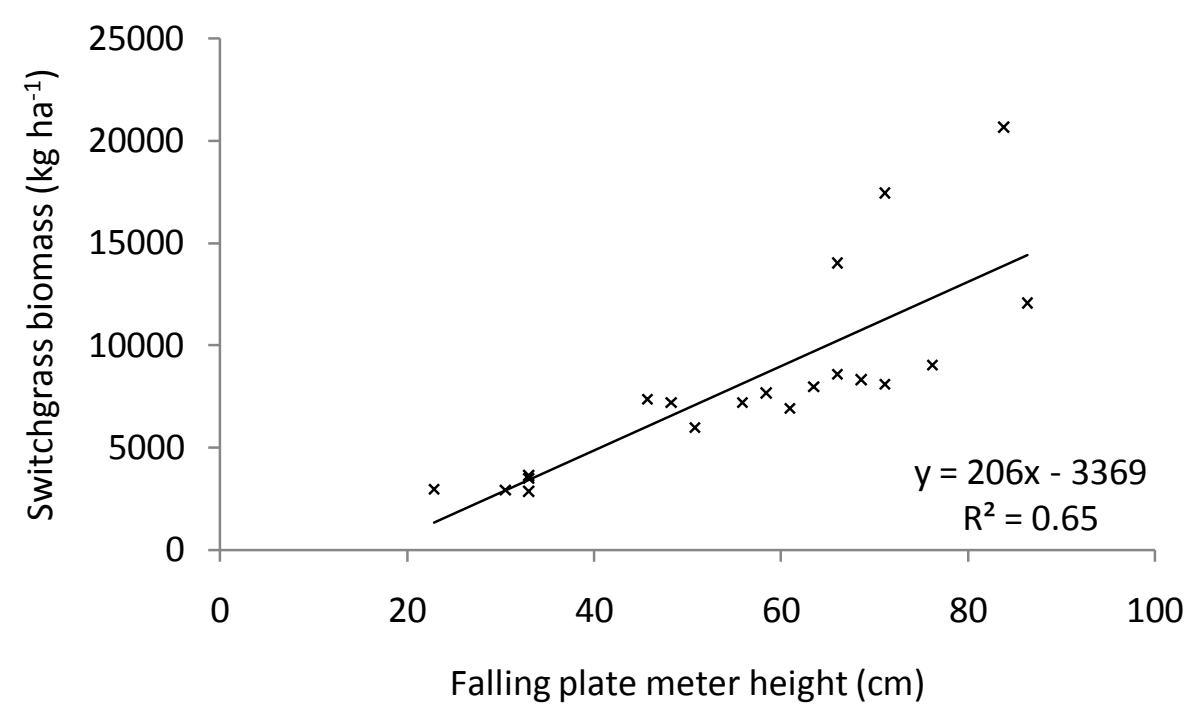

Figure 4-1: Falling plate meter calibration for switchgrass biomass at Hunting Hills.

\subsubsection{Soil properties}

Mehlich 1 extractable soil nutrients for both depths $(0-15 \mathrm{~cm}$ and $15-30 \mathrm{~cm})$ are shown in Table 4-1. Only $\mathrm{Al}, \mathrm{Ca}$ and $\mathrm{Mg}$ were different between top and bottom samples on the mined plots. Al levels were lower in the top which, when combined with the higher amounts of $\mathrm{Ca}$ and $\mathrm{Mg}$, were most likely the result of lime applications. Unmined plots showed more differentiation within the soil profile with $\mathrm{Mn}, \mathrm{K}, \mathrm{P}, \mathrm{Ni}$, and $\mathrm{Zn}$ all being higher from 0-15 $\mathrm{cm}$ than from 15-30 cm (Table 4-1).

Analyzed between each sampling depth, significant differences existed between mined and unmined plots (Table 4-1). Al, Mn, K, and Zn were lower for mined plots while $\mathrm{Fe}, \mathrm{Ca}, \mathrm{P}$, and $\mathrm{Zn}$ were higher in at least one of the depths sampled. $\mathrm{Ca}$ and $\mathrm{Al}$ differences are most likely due to increased lime applications on mined plots relative to unmined plots. Increased $\mathrm{P}$ in the subsoil of the mined plots may be due to contributions from actively weathering spoil material or 
fertilization of mined plots. This is supported by the establishment study where Hobet 21 had the most unweathered mine soil material and had the highest P levels of the three sites. 
Table 4-1: Mehlich 1 extractable nutrients for mined and unmined soils at $0-15 \mathrm{~cm}$ and 15-30 cm depths.

\begin{tabular}{|c|c|c|c|}
\hline Element & Depth & Mined & Unmined \\
\hline & $\mathrm{cm}$ & ----------- & -------- \\
\hline \multirow[t]{2}{*}{$\mathrm{Ca}$} & $0-15$ & $6.7 * \dagger$ & 3.3 \\
\hline & $15-30$ & $2.2 *$ & 1.7 \\
\hline \multirow[t]{2}{*}{$\mathrm{Mg}$} & $0-15$ & $0.5 \dagger$ & 0.5 \\
\hline & $15-30$ & 0.3 & 0.4 \\
\hline \multirow[t]{2}{*}{ K } & $0-15$ & $0.1 *$ & $0.2 \dagger$ \\
\hline & $15-30$ & 0.1 & 0.1 \\
\hline \multirow[t]{2}{*}{$\mathrm{Na}$} & $0-15$ & 0.02 & 0.02 \\
\hline & $15-30$ & 0.02 & 0.02 \\
\hline \multirow[t]{2}{*}{$\mathrm{Al}$} & $0-15$ & $75.6 * \dagger$ & 272 \\
\hline & $15-30$ & $124 *$ & 234 \\
\hline \multirow[t]{2}{*}{$\mathrm{Fe}$} & $0-15$ & $47.1 * \dagger$ & 25.7 \\
\hline & $15-30$ & $52.6^{*}$ & 21.5 \\
\hline \multirow[t]{2}{*}{$\mathrm{Mn}$} & $0-15$ & $14.2 *$ & $52.6 \dagger$ \\
\hline & $15-30$ & $10.4 *$ & 24.7 \\
\hline \multirow[t]{2}{*}{$\mathrm{P}$} & $0-15$ & 4.6 & $3.1 \dagger$ \\
\hline & $15-30$ & $2.9 *$ & 0.8 \\
\hline \multirow[t]{2}{*}{$\mathrm{Ni}$} & $0-15$ & 0.4 & $0.5 \dagger$ \\
\hline & $15-30$ & 0.4 & 0.3 \\
\hline \multirow[t]{2}{*}{$\mathrm{Cu}$} & $0-15$ & 0.7 & 0.7 \\
\hline & $15-30$ & $1.0 *$ & 0.6 \\
\hline \multirow[t]{2}{*}{$\mathrm{Zn}$} & $0-15$ & $1.2 *$ & $2.2 \dagger$ \\
\hline & $15-30$ & 1.0 & 0.9 \\
\hline
\end{tabular}

* Denotes statistical significance between mined and unmined soils at $\mathrm{p}=0.05$.

$\uparrow$ Denotes statistical significance between depth sampled at $\mathrm{p}=0.05$ 
Total C was lower in the bottom layer of soil sampled for both mined and unmined plots with an identical difference of $0.9 \%$ (Table 4-2). In addition to total $\mathrm{C}$, all of the mined samples were evaluated for inorganic $\mathrm{C}$, pedogenic $\mathrm{C}$, and geogenic $\mathrm{C}$. On mined plots, inorganic $\mathrm{C}$ and pedogenic $\mathrm{C}$ were both roughly twice as high in the topsoil compared to the subsoil. Geogenic $\mathrm{C}$ was the same at both depths suggesting a relatively even distribution of coal and shale $\mathrm{C}$. The proportion of total $\mathrm{C}$ that was geogenic averaged $47 \%$ and ranged from 21 to $91 \%$. This clearly indicated that geogenic $\mathrm{C}$ can be a significant contribution to soil $\mathrm{C}$ and must be accounted for to accurately determine pedogenic $\mathrm{C}$. The proportion of total $\mathrm{C}$ that was inorganic ranged from 0 to $15 \%$ and averaged $7 \%$, indicating that it can also be a significant contributor to total $\mathrm{C}$. The proportion of geogenic $\mathrm{C}$ as a part of total $\mathrm{C}$ was higher in the subsoil because of the lower total $\mathrm{C}$ amounts. There was no difference in the relative proportion of inorganic $\mathrm{C}$ between depths. On mined plots, $\mathrm{pH}$ was statistically lower in the subsoil. This was once again probably the result of contact with lime which altered the topsoil $\mathrm{pH}$. On unmined plots, EC was statistically lower in the subsoil.

Electrical conductivity and total $\mathrm{C}$ were higher in mined versus unmined soils (Table 4-2). The increase in total $\mathrm{C}$ was due to the presence of carbonates and geogenic $\mathrm{C}$ in the mined plots. Pedogenic C was not different between mined and unmined plots. All of the unmined plots were assumed to have no geogenic $\mathrm{C}$ contamination and only one sample tested positive for the presence of carbonates. This sample was washed three times with $\mathrm{HCl}$ and $\mathrm{C}$ was reanalyzed to determine pedogenic $\mathrm{C}$; however, this adjustment made no statistical difference. The difference in EC may be due to increased ion concentrations contributed from actively weathering spoil in the mined plots. 
Table 4-2: Soil physical and chemical properties for mined and unmined soils at $0-15 \mathrm{~cm}$ and $15-30 \mathrm{~cm}$ depths.

\begin{tabular}{|c|c|c|c|}
\hline Element & Depth & Mined & Unmined \\
\hline & $\mathrm{cm}$ & --------. & oil ------------- \\
\hline \multirow[t]{2}{*}{$\mathrm{pH}$} & $0-15$ & $5.6 * \dagger$ & 5.0 \\
\hline & $15-30$ & 4.6 & 4.8 \\
\hline \multirow[t]{2}{*}{$\mathrm{EC}\left(\mu \mathrm{S} \mathrm{cm}^{-1}\right)$} & $0-15$ & 79.5 & $60.9 \dagger$ \\
\hline & $15-30$ & $72.3 *$ & 34.3 \\
\hline \multirow[t]{2}{*}{$\%$ Total C } & $0-15$ & $3.1 * \dagger$ & $1.7 \dagger$ \\
\hline & $15-30$ & $2.2 *$ & 0.8 \\
\hline \multirow[t]{2}{*}{$\%$ Inorganic $\mathrm{C}$} & $0-15$ & $0.3 * \dagger$ & 0.004 \\
\hline & $15-30$ & $0.1 *$ & 0 \\
\hline \multirow[t]{2}{*}{ \% Pedogenic C } & $0-15$ & $1.7 \dagger$ & $1.7 \dagger$ \\
\hline & $15-30$ & 0.8 & 0.8 \\
\hline \multirow[t]{2}{*}{ \% Geogenic C } & $0-15$ & 1.2 & Not measured \\
\hline & $15-30$ & 1.2 & Not measured \\
\hline \multirow[t]{2}{*}{$\%$ Fines } & $0-15$ & 74.1 & 77.8 \\
\hline & $15-30$ & 75.5 & 74.5 \\
\hline
\end{tabular}

* Denotes statistical significance between mined and unmined soils at $\mathrm{p}=0.05$.

$\dagger$ Denotes statistical significance between depth sampled at $\mathrm{p}=0.05$

\subsubsection{Biomass production}

Compared using log transformed data, switchgrass biomass was higher on unmined plots than mined plots with production of $8362 \mathrm{~kg} \mathrm{ha}^{-1}$ to $5553 \mathrm{~kg} \mathrm{ha}^{-1}$, respectively. When looking at soil properties and their correlation with biomass across depth of sample and mining treatment, some significant relationships appeared (Table 4-3). The strongest of which are the relationships between $\mathrm{pH}$ and $\mathrm{Ca}$ levels to biomass in the mined topsoil. Electrical conductivity is also related to a lesser extent. These factors would suggest that on these plots soil $\mathrm{pH}$ is a limiting factor to 
switchgrass performance and that lime application has been successful at increasing switchgrass performance. Similar responses to lime were also recorded by Jung et al. (1988) in switchgrass stands also located in southwestern PA. Pedogenic C in the topsoil was also correlated to higher biomass in mined plots. This suggests that on mined plots switchgrass is benefiting from the positive soil qualities associated with higher pedogenic $\mathrm{C}$ contents, like increased water holding capacity and nutrient availability. Since there was no attendant relationship in unmined plots, it could be hypothesized that the increase in pedogenic $\mathrm{C}$ was not just due to increased plant matter turnover in higher yielding plots. This would mean that on the mined sites, switchgrass biomass was being positively influenced by higher pedogenic $\mathrm{C}$ and that high pedogenic $\mathrm{C}$ was not necessarily the result of high switchgrass biomass. More research would be needed to completely confirm this hypothesis. An alternate hypothesis is discussed below. Percent fines was weakly correlated to biomass in the unmined topsoil while Ni was weakly negatively correlated in the unmined subsoil. Biomass was unrelated to stand age in both mined and unmined plots suggesting that soil fertility was influencing biomass more than the age of the stand (Table 4-4). 
Table 4-3: Significant correlations between soil properties and log transformed biomass.

\begin{tabular}{cc}
\hline Soil Property & Correlation Coefficient \\
\hline Mined 0-15 cm & \\
$\mathrm{Ca}^{*}$ & 0.57 \\
$\mathrm{pH}$ & 0.58 \\
$\mathrm{EC}$ & 0.36 \\
Total C & 0.37 \\
Pedogenic C & 0.63 \\
Mined $15-30 \mathrm{~cm}$ & \\
None significant & \\
Unmined 0-15 cm & \\
$\%$ Fines & 0.33 \\
Unmined $15-30 \mathrm{~cm}$ & \\
Ni & -0.34 \\
\hline
\end{tabular}

* All properties listed are significant at $\mathrm{p}=0.05$ for the $\mathrm{R}^{2}$ values shown using log transformed biomass.

\subsubsection{Effects on soil C concentrations}

Pedogenic C concentration was uncorrelated with stand age in either mined or unmined plots. Figure 4-2 and Table 4-4 display the pedogenic $\mathrm{C}$ concentrations for mined and unmined plots at both depths of sampling arranged by the date of switchgrass establishment. Since no trends were apparent, this would indicate that stand age was not the main factor that determined pedogenic $\mathrm{C}$ concentration. This is not totally unexpected since stand age does not represent the amount of $\mathrm{C}$ present at the time of switchgrass establishment and so is not the best indicator of how much soil $\mathrm{C}$ has been deposited as a result of switchgrass growth. Other soil factors and the $\mathrm{C}$ concentration at establishment are probably the largest influence on current pedogenic $\mathrm{C}$. Lemus and Lal (2005) and Bransby et al., (1998) both point out that positive soil C sequestration with switchgrass could only be achieved in soils that were first degraded in C. It is possible that pedogenic $\mathrm{C}$ concentrations on these soils have reached equilibrium within the depth measured. 
This is supported by the fact that pedogenic $\mathrm{C}$ concentrations are nearly identical between mined and unmined soils. If pedogenic $\mathrm{C}$ levels were lower for mined areas, it could be argued that those soils still had the capacity to sequester $\mathrm{C}$ until they reached equilibrium, which would presumably be about the level of the surrounding unmined areas. Since mining was completed in the 1960's this site has had decades to recoup C losses from disturbance. If these soils are not saturated in $\mathrm{C}$ then the rate of sequestration by switchgrass is indistinguishable from the sequestration rate in the previous cool season grass cover.

Table 4-4: Nontransformed Switchgrass biomass and pedogenic $\mathrm{C}$ at two sampling depths by stand age.

\begin{tabular}{cccc}
\hline $\begin{array}{c}\text { Year of } \\
\text { Establishment }\end{array}$ & Biomass* $^{*}$ & $\begin{array}{c}0-15 \mathrm{~cm} \\
\text { Pedogenic C }\end{array}$ & $\begin{array}{c}15-30 \mathrm{cml} \\
\text { Pedogenic C }\end{array}$ \\
\hline Mined & --- kg ha $^{-1}--$ & -------- & \% \\
1991 & 6123 & 1.24 & 1.41 \\
1994 & 6069 & 2.00 & 0.73 \\
1995 & 5808 & 1.44 & 0.47 \\
1999 & 4007 & 1.46 & 0.76 \\
2004 & 2811 & 1.32 & 0.66 \\
2008 & 9750 & 2.52 & 0.39 \\
2008 & 7604 & 2.26 & 1.04 \\
Unmined & & & 0.63 \\
1995 & 7302 & 1.46 & 0.98 \\
2000 & 8650 & 1.68 & 0.81 \\
2000 & 10530 & 2.28 & 0.82 \\
2002 & 5067 & 1.97 & 0.90 \\
2002 & 11075 & 1.79 & 0.63 \\
2004 & 10906 & 1.43 & 0.81 \\
2005 & 9685 & 1.35 & \\
\hline
\end{tabular}

* Biomass data presented here is untransformed. 


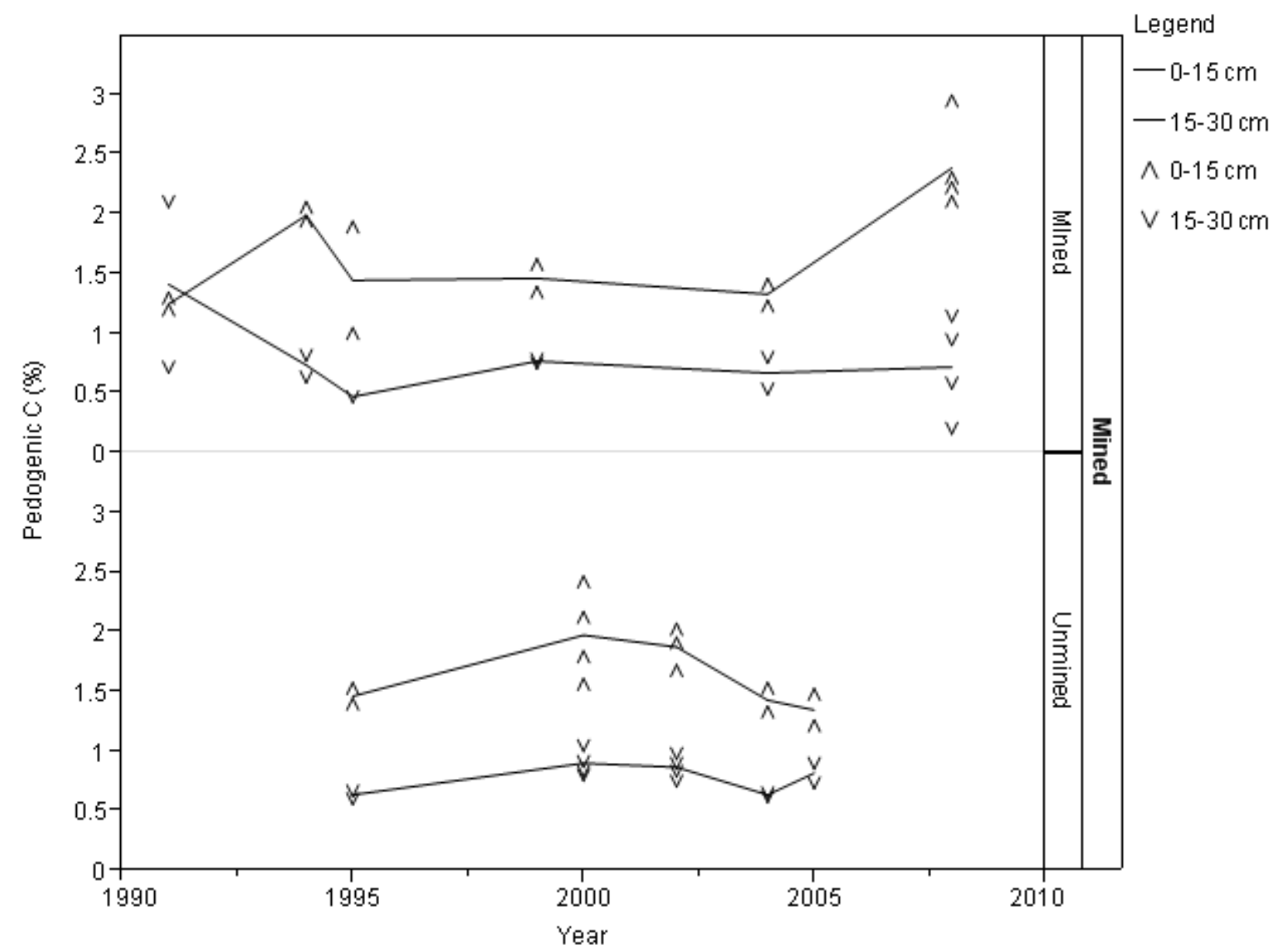

Figure 4-2: Pedogenic $\mathrm{C}$ for two sampling depths by stand age on mined and unmined soils.

Soil pedogenic $\mathrm{C}$ is a function of a variety of factors, of which plant growth is only one. Landscape position, management, moisture regimes, $\mathrm{pH}$, and nutrient availability all play a role in governing soil pedogenic C (Lemus and Lal, 2005; Bransby et al., 1998). At this particular research area, some of these other factors which were measured were found to relate to pedogenic $\mathrm{C}$ contents while stand age was not (Table 4-5). None of the factors measured were correlated with soil $\mathrm{C}$ in the unmined plots. Only $\mathrm{pH}$ was correlated for both mined topsoil and subsoil, while Ca and EC were also correlated in the topsoil. Organic matter is known to increase buffering capacity of soils; however Ca and EC correlations strongly suggest the influence of 
lime applications. This implies that liming the acid soils on the unmined plots was having a positive effect on pedogenic $\mathrm{C}$ levels. It is unclear by what mechanism $\mathrm{pH}$ could be affecting pedogenic $\mathrm{C}$ except through influencing plants or other soil organisms. Since biomass was correlated with $\mathrm{pH}$ in unmined plots (Table 4-3) it may in fact be that high biomass is creating higher pedogenic $\mathrm{C}$ through increased plant litter turnover, despite the lack of a similar trend seen in unmined plots. This would be the alternative to the hypothesis discussed above where pedogenic $\mathrm{C}$ was influencing yield and not the other way around. However, soil $\mathrm{pH}$ is known to influence other soil factors which could be having an effect on pedogenic C. While the significant correlations listed below by no means strictly govern soil $\mathrm{C}$ levels, they do offer a glimpse into the variety of factors which influence soil C regimes.

Table 4-5: Significant correlations between soil properties and pedogenic C.

\begin{tabular}{cc}
\hline Soil Property & Correlation Coefficient \\
\hline Mined Top & \\
$\mathrm{Ca}$ & 0.66 \\
$\mathrm{pH}$ & 0.46 \\
$\mathrm{EC}$ & 0.54 \\
pH & 0.34 \\
Mined Bottom & \\
Unmined Top & \\
None significant & \\
Unmined Bottom & \\
None Significant & \\
* All properties listed are significant at $\mathrm{p}=0.05$ for \\
the $\mathrm{R}^{2}$ values shown
\end{tabular}

\subsection{Conclusions}

The $\mathrm{C}$ sequestration portion of this study showed that stand age was not the most important factor in determining organic $\mathrm{C}$ concentrations under switchgrass stands. On mined soils, the soil properties with the highest correlation to pedogenic $\mathrm{C}$ concentrations and biomass 
production were those related to soil $\mathrm{pH}$ suggesting that soil acidity was a limiting factor at the Hunting Hills site. In general it was shown that while total $\mathrm{C}$ was higher on mined areas, soil organic $\mathrm{C}$ was about equal after subtracting for geogenic $\mathrm{C}$. Pedogenic $\mathrm{C}$ was always higher in the topsoil in both mined and unmined areas, and there was an even distribution of geogenic $\mathrm{C}$ with depth of soil sampled on the mined areas. While stand age was not correlated with pedogenic $\mathrm{C}$ in mined areas, switchgrass biomass was. This suggests that either high biomass was creating higher $\mathrm{C}$ concentrations through increased plant litter turnover, or that high $\mathrm{C}$ concentrations were favoring greater switchgrass biomass productions through more favorable edaphic conditions. More research is needed to determine the direction and nature of this causal relationship. 
5. Evaluation of the Chemi-Thermal Method to Determine Geogenic C in Mine Soils.

\subsection{Introduction and objectives}

Accurately measuring soil organic $\mathrm{C}$ (SOC) in mine soils is made more difficult by the presence of inorganic $\mathrm{C}$ from carbonates and geogenic $\mathrm{C}$ from carbonaceous rock material like coal and black shale. Carbonates are easily removed by reacting soil samples with acid, but determining geogenic $\mathrm{C}$ is much more difficult. Measuring the age of $\mathrm{C}$ in the samples with $\mathrm{C}$ isotope mass spectrometry can accurately differentiate between organic materials deposited recently by organisms and geologic organic material in coal and shale deposited in ancient times. Unfortunately, this method is very costly and restricted to only a handful of labs worldwide.

A method capable of being performed in the average soil research laboratory is needed to accurately differentiate between carbonate $\mathrm{C}$, soil organic $\mathrm{C}$, and coal or shale organic $\mathrm{C}$. There is no firmly established method in the literature to accomplish this, but a new method used by Ussiri and Lal (2008) seems to be the most popular. This method relies on the relative increased resistance of coal $\mathrm{C}$ to oxidation to distinguish it from SOC and uses equipment and reagents found in most soil research laboratories. The authors purport good ability to detect coal $\mathrm{C}$ in mine soils, but they make no mention of being able to determine geogenic $\mathrm{C}$ from shale.

In reality, coal is not the only geogenic $\mathrm{C}$ source present in mine soils. Other overburden materials can also contain significant amounts of geogenic $\mathrm{C}$, specifically carbonaceous rocks like shale. Because the chemi-thermal method uses $\mathrm{HF}$ to remove silicates and release organic $\mathrm{C}$ bound to the soil's mineral matrix, it could also be that the HF treatment is releasing geogenic $\mathrm{C}$ from shale and other types of carbonaceous rock material present in mine soils. This notion was first considered while processing mine soil samples and two interesting observations were made. 
First, significant amounts of mass loss of samples were recorded before and after using the method. Second, visual observations of the color of decanted fluids seemed to indicate that more $\mathrm{C}$ was being removed by the method after treatment with HF. This release of $\mathrm{C}$ from carbonaceous materials is significant because it would cause an overestimation of SOC since it is determined by subtracting inorganic and geogenic $\mathrm{C}$ from total $\mathrm{C}$. The amount of geogenic $\mathrm{C}$ released could significantly alter the results of any $\mathrm{C}$ sequestration study that utilizes this method.

Although the chemi-thermal method is attractive in that it can be carried out in the typical soil research laboratory, it should also be noted that the extreme amount of time the method requires limits the number of samples that can be processed with this method. The minimum amount of time devoted to the actual chemical and thermal treatments is $31.75 \mathrm{hr}$. To that has to be added two $48 \mathrm{hr}$ drying periods and time to weigh, decant, grind, transfer and process samples in the lab. The method requires centrifuging a total of 19 separate times. The use of concentrated $\mathrm{HNO}_{3}$ and dilute $\mathrm{HF}$ also makes it relatively dangerous.

A small methodological experiment was designed to test the hypothesis that the chemithermal method was releasing geogenic $\mathrm{C}$ from shale materials. Since this was thought to be occurring, another experiment was conducted to test the hypothesis that simple thermal oxidation would be able to produce results comparable to the chemi-thermal method with much less time and effort. A high throughput of samples could be achieved using a simple thermal oxidation technique since sample process time is reduced from about a week to only a few hours without the use of any dangerous reagents. 


\subsection{Literature review}

While there is no established method in the literature to determine coal $\mathrm{C}$ in the average soil research laboratory, the chemi-thermal method of Ussiri and Lal (2008) seems to be the most popular. This method and others extremely similar to it have been used by these authors and others to determine coal C and soil organic C in mine soils (Chatterjee et al., 2009; Shukla and Lal, 2005; Ussiri et al., 2006a; Ussiri et al., 2006b). Other very similar chemi-thermal methods have also been employed to quantify black carbon (BC) in soils (He and Zhang, 2009; Kuhlbush, 1995; Rawlins, 2008; Schmidt et al., 2001).

In their paper, Ussiri and Lal report a strong correlation between data obtained with the chemi-thermal method and $\mathrm{C}$ isotope analysis suggesting the method does accurately measure coal $\mathrm{C}$ in mine soils. They also report that coal was relatively unaffected by the method and retained about $98.5 \%$ of its mass. Additionally they used the method to measure the amount of coal $\mathrm{C}$ added to manufactured coal:soil standards. They reported consistent and reliable coal $\mathrm{C}$ levels could be measured and a slight overestimation of coal $\mathrm{C}$ may occur due to the inability of the method to completely remove a very small fraction of highly resistant SOC. In an attempt to reduce the amount of extremely recalcitrant SOC in the sample, HF is used to demineralize the sample and release SOC that may be inextricably bound to the mineral matrix.

However, the use of HF in their method may represent a potential source of error in mine soils that contain carbonaceous materials other than coal. Mine soils frequently contain carbonaceous materials consisting of not only coal, but also black shale (Haering et al., 2004). $\mathrm{HF}$ is commonly used as a sample pretreatment in magnetic resonance spectroscopy to remove minerals and paramagnetic materials from samples. Schmidt and Gleixner (2005) used an HF 
pretreatment on two organic black shales from Germany to compare mass loss and effects on organic C. Both shales lost a significant amount of mass (83\% and 92\%) from soaking in $10 \%$ $\mathrm{HF}$ for $36 \mathrm{hr}$. Concentrations of $\mathrm{C}$ in the shales were measured before and after the HF treatment. One shale was enriched in $\mathrm{C}$ and the other was depleted. The amount of $\mathrm{C}$ lost in both cases indicated that the HF wash was releasing C from shale material. Schmidt et al. (2001) compared the chemi-thermal method of Kuhlbush (1995) with and without HF to determine BC in soils as a treatment to remove silicates. In six of the eight soils they measured, $\mathrm{BC}$ was reduced with the HF treatment. It is unclear, however, if this reduction is the result of the HF treatment releasing $\mathrm{BC}$ or producing the desired effect of releasing otherwise inextricably bound SOC. Kuhlbush uses a method very similar to Ussiri and Lal except that his method excludes the use of HF and thermally treats the samples at $340^{\circ} \mathrm{C}$ for $2 \mathrm{hr}$ instead of $3 \mathrm{hr}$.

Rawlins et al. (2008) used a simple thermal oxidation step at $450^{\circ} \mathrm{C}$ for $8 \mathrm{hr}$ to determine $\mathrm{BC}$ in urban soils. They compared this to $\mathrm{BC}$ data obtained from the same samples using the chemi-thermal oxidation technique of Kuhlbush (1995). This comparison yielded a very high correlation $\left(\mathrm{r}^{2}=0.97\right)$ suggesting that both methods could be used to determine $\mathrm{BC}$ in soils. They also reported that the thermal oxidation technique at $450^{\circ} \mathrm{C}$ consistently oxidized an extra portion of BC not removed by the chemi-thermal method. Schmidt et al. (2001), in a comparison of six different methods of determining $\mathrm{BC}$, reported that values obtained by thermally oxidizing samples at $375^{\circ} \mathrm{C}$ for $24 \mathrm{hr}$ were always higher than values obtained with the same chemithermal method. This would suggest that BC oxidation is temperature dependant.

Regardless of the method used, geogenic $\mathrm{C}$ is always operationally defined by the amount of $\mathrm{C}$ left in the sample after chemical or thermal treatments. Assuming that these methods may be affecting coal or shale $\mathrm{C}$, quantitative values could be obtained if a correction for $\mathrm{C}$ loss in 
geogenic materials was accounted for in specific mine spoils. This method was proposed by Amichev (2007) using only a thermal oxidation step. Results in this study showed that C loss in coal materials was related to time and temperature of oxidation as well as to specific types of coal and overburden material mixtures. The thermal oxidation procedure employed by Amichev was $375^{\circ} \mathrm{C}$ for $24 \mathrm{hr}$ and nearly all of the pedogenic and geogenic $\mathrm{C}$ in the samples was oxidized. Using C loss determinations of pure coal-free mine soil and coal material independently, Amichev was able to correct for this and produce an estimate of geogenic and pedogenic $\mathrm{C}$.

\subsection{Materials and methods}

Total soil C was determined using a LECO TruSpec CHN elemental analyzer (LECO Corp., St Joseph, MI). Soil was ground with a porcelain mortar and pestle to pass a US \#60 sieve $(<0.250 \mathrm{~mm})$. Each sample was weighed into foil cups and combusted at $950^{\circ} \mathrm{C}$ to determine total $\mathrm{C}$. The amount of $\mathrm{C}$ in the form of evolved $\mathrm{CO}_{2}$ was measured using an infrared gas spectrometer. Combustion at this temperature would liberate all forms of $\mathrm{C}$ present in the sample.

To determine what proportion of the total $\mathrm{C}$ was composed of inorganic $\mathrm{C}$, pedogenic $\mathrm{C}$ and geogenic C, the wet chemical and thermal extraction method of Ussiri and Lal (2008) was used to distinguish between $\mathrm{C}$ pools (Figure 5-1). 


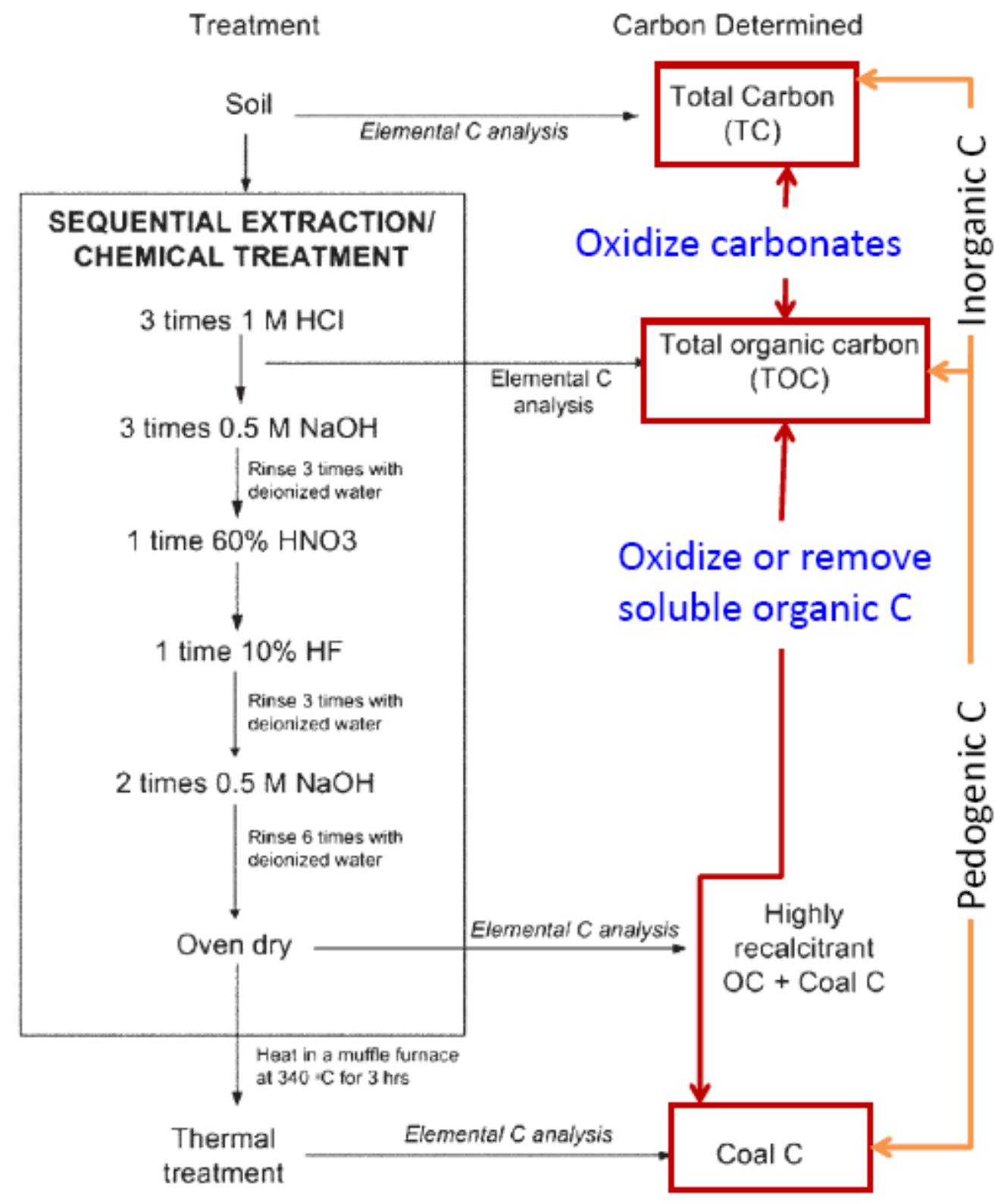

Figure 5-1: Chemi-thermal method schematic (Ussiri and Lal, 2008).

The basic process for the method as described by Ussiri and Lal (2008) is as follows: $2 \mathrm{~g}$ of soil were placed in plastic centrifuge tubes and allowed to react with $20 \mathrm{~mL}$ of $1 \mathrm{M} \mathrm{HCl}$ for 30 min before being centrifuged and decanted. This process was repeated twice for a total of three washings. Samples were placed in a drying oven at $60^{\circ} \mathrm{C}$ for $48 \mathrm{hr}$, ground with a mortar and 
pestle and a portion of the sample was analyzed again with the LECO CHN analyzer to determine inorganic $\mathrm{C}$ by difference.

Samples were then reacted with $20 \mathrm{~mL} 0.5 \mathrm{M} \mathrm{NaOH}$ one time for $15 \mathrm{hr}$ and twice more for $1 \mathrm{hr}$ on a shaking table. Then samples were reacted with $20 \mathrm{~mL} 60 \% \mathrm{HNO}_{3}$ one time for 15 min on a shaking table. Next, samples were reacted once with $20 \mathrm{~mL} 10 \% \mathrm{HF}$ for $4 \mathrm{hr}$ with intermittent shaking to release mineral bound organic matter. Samples were then reacted with 20 $\mathrm{mL} 0.5 \mathrm{M} \mathrm{NaOH}$ twice for 30 min and then washed six times with DI water. Finally coal C was determined by thermally oxidizing the sample in a muffle furnace at $340^{\circ} \mathrm{C}$ for $3 \mathrm{hr}$ and determining total $\mathrm{C}$ in the remaining sample by dry combustion with the LECO CHN analyzer.

To check the validity of the method, a small batch of coal and soil standards were constructed using carbonate free soil and a mixture of coal collected from washed coarse material obtained during determination of percent fines. Both coal and soil were ground with a mortar and pestle to pass through a US \#60 sieve $(<0.250 \mathrm{~mm})$ sieve. Coal was then carefully weighed into the soil at a rate of $0.5 \%, 2.5 \%$ and $5 \%$ by weight. These samples were mixed by hand in bottles to create a homogenous mixture.

Analysis of these first standards left some issues unresolved so a small experiment was designed to test the hypothesis that different carbonaceous materials would respond differently to the chemi-thermal method, and that similar results could be obtained using just a thermal oxidation technique.

To examine the effect of the chemi-thermal method on pure geogenic materials, four types of geogenic $\mathrm{C}$ materials were subjected to the treatment. The first was the pure coal mentioned above and the other three were carbonaceous materials collected from the coarse 
fragments at each of the establishment sites that included coal and black shale. Enough material was ground to pass between $0.25 \mathrm{~mm}$ and $0.1 \mathrm{~mm}$ sieves to make two $1 \mathrm{~g}$ samples.

To further test the hypothesis that the chemi-thermal method was releasing geogenic C from carbonaceous materials and to test the hypothesis that simple thermal oxidation could be a tool for measuring geogenic C, two more groups of standards were manufactured. Enough carbonate free soil was ground to pass through a US \#60 seieve $(<0.250 \mathrm{~mm})$ to create seven 100 g standards: one coal free blank, and two standards of different geogenic materials at each of $0.5 \%, 2.5 \%$ and $5 \%$ carbonaceous material by weight. The two geogenic $\mathrm{C}$ materials chosen were a "pure" coal material that did not contain any other carbonaceous rocks, and the black coal and shale mixture contained in coarse fragments from the Hampshire Hill site. Visual observation of these coarse fragments showed large amounts of both lustrous coal and dull black shale. These geogenic $\mathrm{C}$ materials were ground and sieved to be between $0.25 \mathrm{~mm}$ and $0.1 \mathrm{~mm}$ in size. A lower limit was placed on particle size because of the extremely difficult process of centrifuging coal particles that tend to float. While this is not truly representative of the geogenic C present in mine soils which could have smaller particle sizes, it was deemed preferable to prevent $\mathrm{C}$ losses from decanting that would be unrelated to the actual chemi-thermal process. The standards were shaken by hand and then passed through a vibrating sample splitter and recombined five times to ensure a homogenous mixture. These standards were analyzed using the chemi-thermal method and were also subjected to a simple thermal oxidation at two temperatures and time periods. Samples were thermally oxidized at $340^{\circ} \mathrm{C}$ for $3 \mathrm{hr}$ and also at $360^{\circ} \mathrm{C}$ for $4 \mathrm{hr}$. The remaining $\mathrm{C}$ in the samples after this treatment was classified as geogenic $\mathrm{C}$. A comparison of these methods was made on both standards. 
Analysis of covariance (ANCOVA) was used to compare the amount of geogenic C measured by each method to the amount actually added to the standard. ANCOVA in this situation was used to test for homogeneity of slopes. First, each standard was measured for total $\mathrm{C}$ before any method was applied. Total $\mathrm{C}$ in each group of standards was plotted against the amount of carbonaceous material added. The slope of this line was equal to the percentage $\mathrm{C}$ in the carbonaceous material used and the intercept was equal to the SOC in the soil material used. Both of these figures were confirmed by measuring the percent $\mathrm{C}$ of the carbonaceous material and the pure soil independently. This determined the amount of $\mathrm{C}$ added to each standard that was geogenic in nature. Then, the amount of geogenic $\mathrm{C}$ in each sample for each of the methods was plotted against the amount of carbonaceous material mixed with the soil to obtain regression equations for each method in each standard. These equations developed for each method were then compared with ANCOVA to the geogenic $\mathrm{C}$ added equation for all three standards. Significance was determined at $\mathrm{p}<0.05$ and Tukey's Honestly Significant Difference test was used post hoc to determine separation of means.

\subsection{Results and discussion}

To first test the ability to produce accurate results with the chemi-thermal method to determine soil $\mathrm{C}$ contents, four standards were made using 1) a carbonate free soil and 2) three added levels of geogenic C (GC) containing carbonaceous coal and shale. Three replications of these standards and a geogenic $\mathrm{C}$ free blank were used. The results of these standards are in Table 5-1 and include the amount of actual geogenic $\mathrm{C}$ measured at the end of the method as well as the percentage of the added geogenic $\mathrm{C}$ that was reported with each method. At the highest level of $5 \%$ by weight, the chemi-thermal method measured $97 \%$ of the added geogenic 
C. The relative standard deviation from the mean (RSD) for each standard was between $5.6 \%$ and $17.7 \%$.

A comparison of the linear regressions obtained from the $\mathrm{C}$ added compared to the $\mathrm{C}$ measured are shown in Figure 5-2. The slope of the GC added line is equal to the percentage $\mathrm{C}$ of the carbonaceous material added. ANCOVA showed no significance for homogeneity of slopes, meaning the two regressions were not statistically different. However, the slight change in slope and the increasing accuracy of the method as added C levels were increased suggest that the method was having an effect on geogenic C. This was visually observed when decanting soluble $\mathrm{C}$ from the samples during the procedure. Samples with higher amounts of carbonaceous material were darker in color suggesting the method was releasing more $\mathrm{C}$ from these materials. Because of these observations, it was decided to further examine the accuracy of this method.

Table 5-1:Chemi-thermal method detection of added geogenic $\mathrm{C}$ in manufactured carbonaceous material:soil standards. Group one.

\begin{tabular}{|c|c|c|c|c|}
\hline $\begin{array}{c}\text { Carbonaceous } \\
\text { material } \\
\text { added }\end{array}$ & $\begin{array}{c}\text { Geogenic } \mathrm{C} \\
\text { added }\end{array}$ & $\begin{array}{c}\text { Geogenic C } \\
\text { measured }\end{array}$ & $\begin{array}{c}\text { Percent of } \\
\text { added geo. C } \\
\text { reported }\end{array}$ & RSD \\
\hline \multicolumn{5}{|c|}{ - } \\
\hline 0 & 0 & 0.17 & & 14.7 \\
\hline 0.5 & 0.35 & 0.24 & 69 & 17.7 \\
\hline 2.5 & 1.6 & 1.3 & 81 & 5.6 \\
\hline 5 & 3.4 & 3.3 & 97 & 12.9 \\
\hline
\end{tabular}




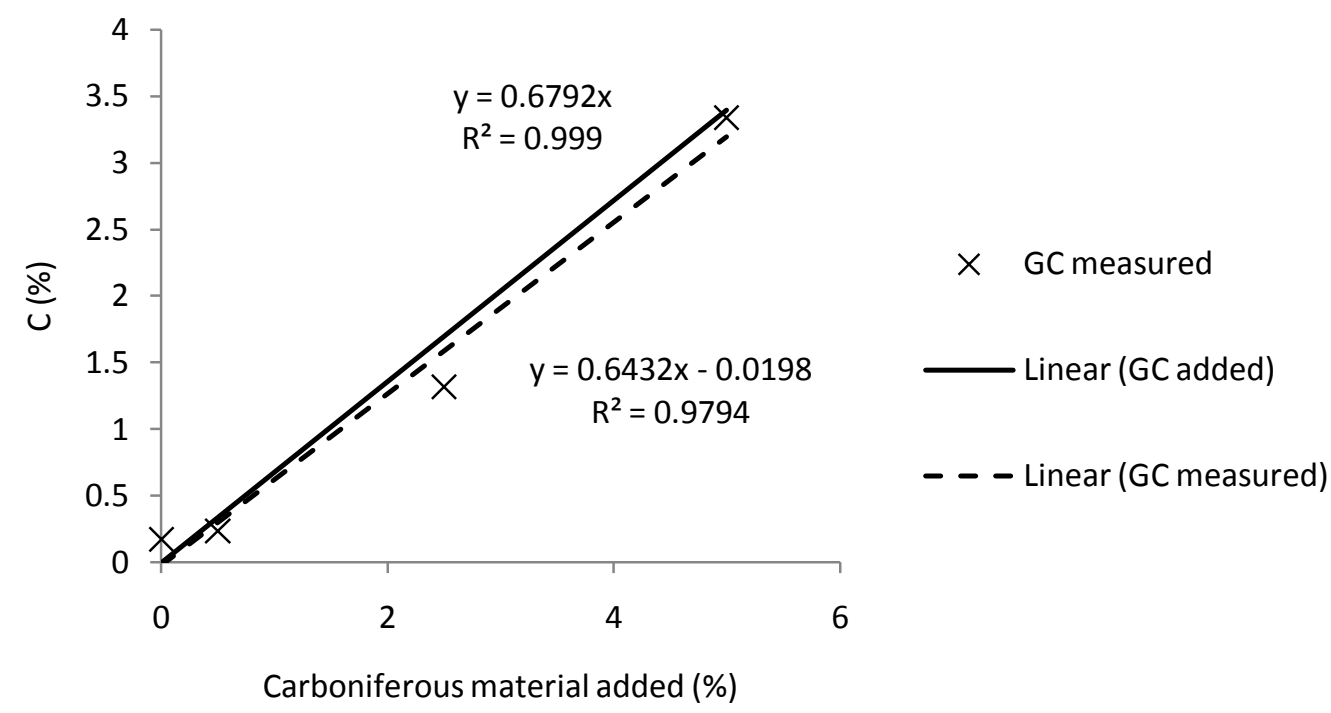

Figure 5-2: Chemi-thermal method detection of added geogenic $\mathrm{C}$ in manufactured carbonaceous material:soil standards. Group one.

A group of only geogenic $\mathrm{C}$ material samples with no soil was also analyzed by the chemi-thermal procedure. These materials were the shale and coal individually collected from each of the establishment sites and the last was a sample of pure coal. Each material was replicated for a total of eight samples made up of four carbonaceous materials. Table 5-2 shows the percent $\mathrm{C}$ content before and after the chemi-thermal treatment as well as the percent mass retained. All of the samples lost $\mathrm{C}$ content and lost mass. Figure 5-3 shows the obvious presence of soluble $\mathrm{C}$ in some of the samples after treatment with HF. The pure coal samples on the far right of the photo were nearly clear. Visual observation of the Hampshire Hill coarse fragments indicated that it had a large proportion of dull dark colored organic shale. The material from that site showed the smallest mass of dry matter retained. 
Table 5-2: Chemi-thermal method affect on four carbonaceous materials.

\begin{tabular}{lccc}
\hline & Start C & Finish C & Mass Retained \\
\hline & & $--------------\%$ & -------------- \\
Hobet 21 & 79 & 74 & 60 \\
Coal-Mac & 77 & 71 & 66 \\
Hampshire Hill & 56 & 42 & 36 \\
Pure Coal & 92 & 74 & 63 \\
\hline
\end{tabular}

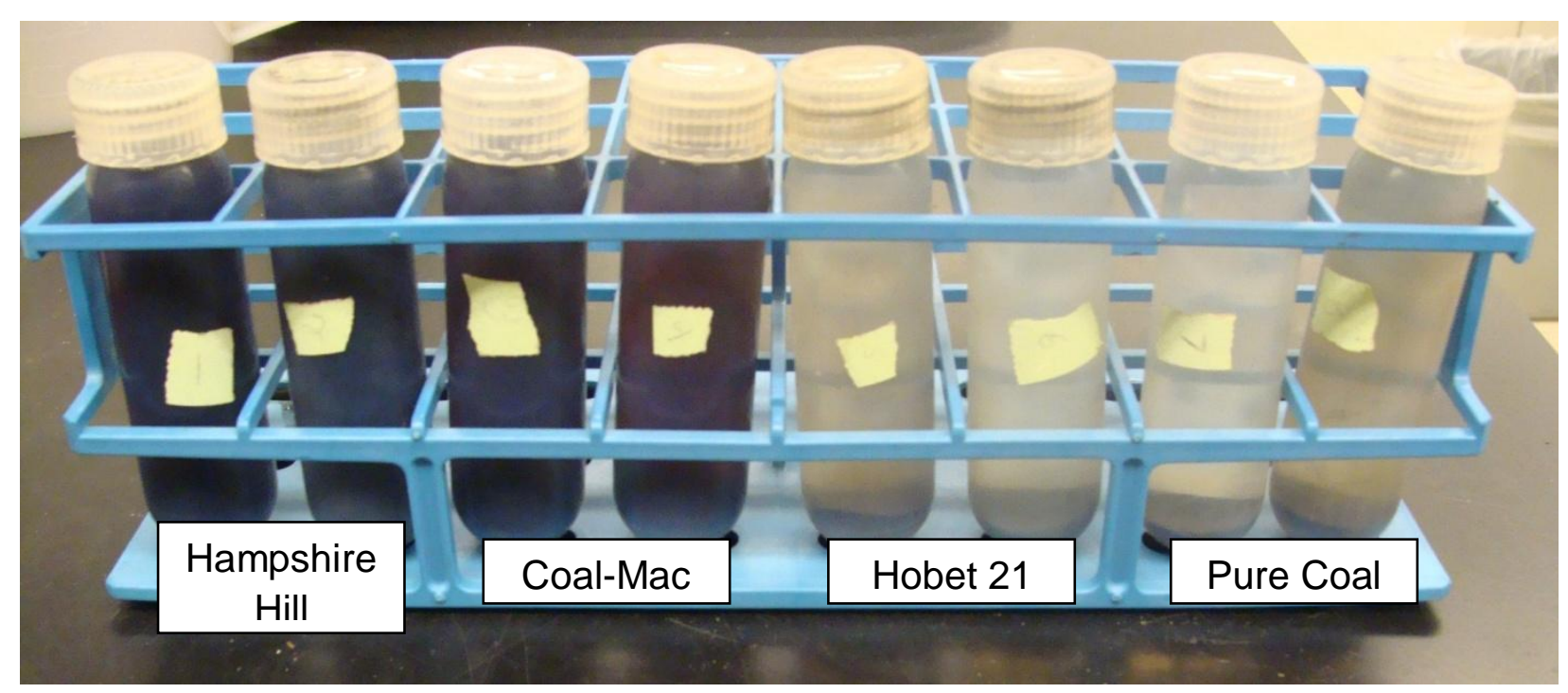

Figure 5-3: C release from the chemi-thermal method on four pure carbonaceous materials.

The results of this experiment were unable to reproduce the relatively small amount of mass loss reported by Ussiri and Lal (2008). Accounting for mass balance during the procedure showed that the three shale and coal mixtures lost dry weight from both the chemical and thermal portions of the method. The pure coal did not lose any mass during the chemical portion which would be in concurrence with Ussiri and Lal, but did lose mass during the thermal oxidation step which is contrary to their findings.

To examine the repercussions of this finding when applied to soil mixtures, seven new $100 \mathrm{~g}$ standards were made: one carbonaceous material free blank, and three standards of two different carbonaceous materials at each of $0.5 \%, 2.5 \%$ and $5 \%$ carbonaceous material by 
weight. The two carbonaceous materials were a "pure" coal material that did not contain any other carbonaceous rocks (pure coal group), and the coal and shale mixture contained in coarse fragments from the Hampshire Hill site (coal and shale group).

Results from the coal group analysis are shown in Table 5-3. All methods were more accurate at measuring added $\mathrm{C}$ at higher concentrations. Relative standard deviations from the mean were much lower for the chemi-thermal method than for the thermal oxidation methods. A likely reason for this is the use of a muffle furnace without even heat distribution for the thermal oxidation methods. Although the chemi-thermal method had the lowest RSD, it was, unfortunately, the least accurate in measuring the actual amount of geogenic $\mathrm{C}$ added (Figure 5-4). An ANCOVA comparison of the regressions obtained from each method is shown in Table 5-4. The slopes of the lines indicate the percentage of $\mathrm{C}$ measured compared to the material added for each method. If all of the methods were equally accurate, there would be no difference between the slopes of the geogenic $\mathrm{C}$ added line and the individual methods for determining geogenic C. All the methods were precise with very good $\mathrm{R}^{2}$ values and modest RSD. This means that the methods were good at detecting changes in geogenic $\mathrm{C}$ concentrations if not their actual values. Thermal oxidation at $340^{\circ} \mathrm{C}$ was the most accurate method because it was closest to the added geogenic $\mathrm{C}$ line. All of the methods were different from the amount of geogenic $\mathrm{C}$ added, and there was no statistical difference between the chemi-thermal method and the oxidation at $360^{\circ} \mathrm{C}$. 
Table 5-3: Chemi-thermal and thermal oxidation method detection of added coal geogenic $\mathrm{C}$ in manufactured carbonaceous material:soil standards.

\begin{tabular}{|c|c|c|c|c|c|c|c|c|c|c|}
\hline \multirow{2}{*}{$\begin{array}{c}\text { Added } \\
\text { material } \\
\text { by weight }\end{array}$} & \multirow{2}{*}{$\begin{array}{l}\text { Geo. C } \\
\text { Added }\end{array}$} & \multicolumn{3}{|c|}{$360^{\circ} \mathrm{C}$ Thermal Oxidation } & \multicolumn{3}{|c|}{$340^{\circ} \mathrm{C}$ Thermal Oxidation } & \multicolumn{3}{|c|}{ Chemi-Thermal } \\
\hline & & $\begin{array}{c}\text { Geo. C } \\
\text { measured }\end{array}$ & $\begin{array}{l}\% \text { of added } \\
\text { reported }\end{array}$ & RSD & $\begin{array}{c}\text { Geo. C } \\
\text { measured }\end{array}$ & $\begin{array}{l}\% \text { of added } \\
\text { reported }\end{array}$ & RSD & $\begin{array}{c}\text { Geo. C } \\
\text { measured }\end{array}$ & $\begin{array}{l}\% \text { of added } \\
\text { reported }\end{array}$ & RSD \\
\hline 0 & 0 & 0.07 & & 25 & 0.08 & & 19 & 0.08 & & 0.1 \\
\hline 0.5 & 0.5 & 0.3 & 54 & 9.1 & 0.4 & 70 & 7.8 & 0.29 & 55 & 2.2 \\
\hline 2.5 & 2.3 & 1.7 & 75 & 7.2 & 2.1 & 93 & 3.6 & 1.4 & 62 & 0.2 \\
\hline 5 & 4.7 & 3.6 & 72 & 11 & 3.8 & 81 & 6.4 & 3.2 & 68 & 1.5 \\
\hline
\end{tabular}

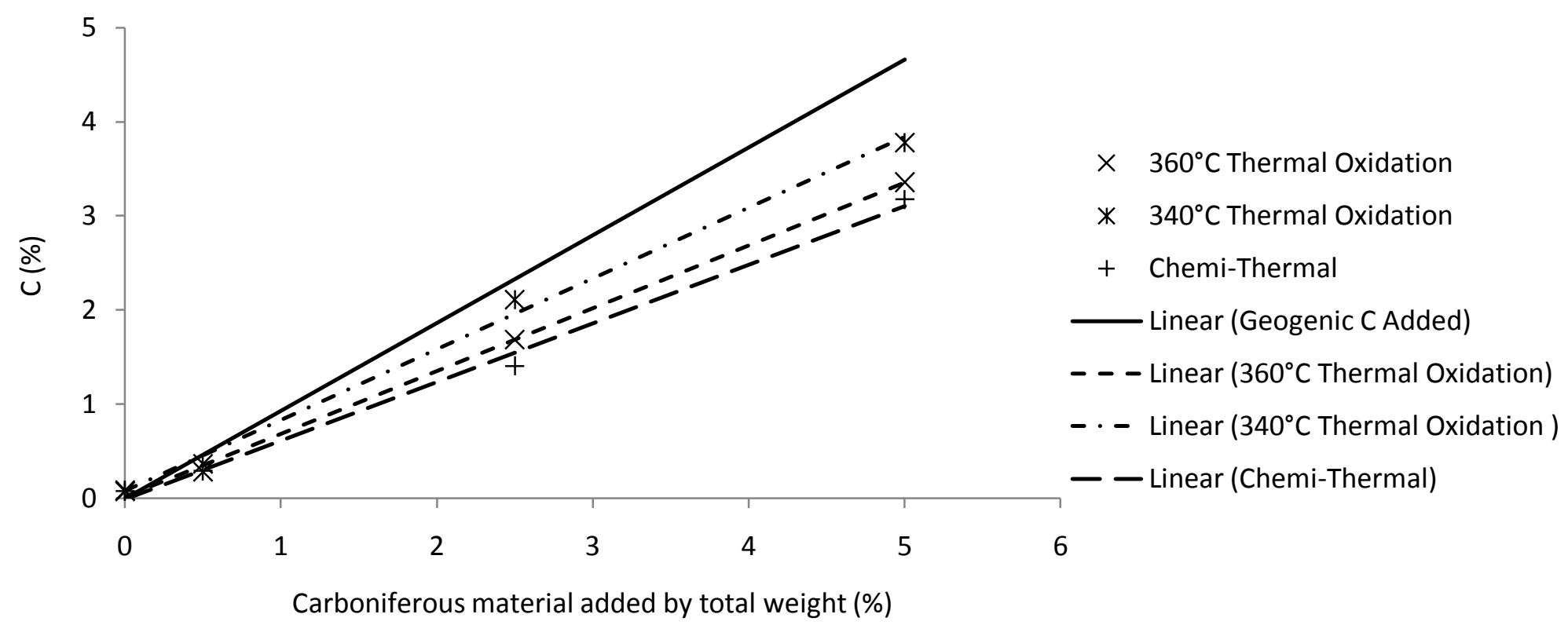

Figure 5-4: Chemi-thermal and thermal oxidation method detection of added coal geogenic $\mathrm{C}$ in manufactured carbonaceous material:soil standards. 
Table 5-4: Linear regression comparison of the chemi-thermal and thermal oxidation methods used to detect added coal geogenic $\mathrm{C}$ in manufactured carbonaceous material:soil standards

\begin{tabular}{lcc}
\hline & Slope of regression & $\mathrm{R}^{2}$ \\
\hline Geo C added & $0.92 \mathrm{a}$ & 0.999 \\
$340^{\circ} \mathrm{C}$ & $0.75 \mathrm{~b}$ & 0.996 \\
$360^{\circ} \mathrm{C}$ & $0.67 \mathrm{c}$ & 0.999 \\
Chemi-thermal & $0.62 \mathrm{c}$ & 0.995 \\
\hline$*$ Values in the same column not covered by the same letter are statistically \\
different at $\mathrm{p}=0.05$.
\end{tabular}

The same analyses were performed for the coal and shale group standards that were made up of geogenic $\mathrm{C}$ from Hampshire Hill consisting of coal and carbonaceous shale. This carbonaceous material had a much lower percent $\mathrm{C}$ than the coal group material. In this group of standards, the proportion of geogenic $\mathrm{C}$ measured by each method increased as concentration decreased (Table 5-5). This was due to the effect of the small amount of residual $\mathrm{C}$ in the soil material that was unoxidized by the different methods. Technically this is pedogenic $\mathrm{C}$, but is operationally defined as geogenic $\mathrm{C}$ because it is left unoxidized after treatment. Its presence can be seen in each of the pure soil blanks. Because of the low amount of $\mathrm{C}$ added, this residual pedogenic $\mathrm{C}$ had a large effect on the measured geogenic $\mathrm{C}$. This led to proportions of geogenic C measured compared to the amount added greater than 100\%. In general, RSD increased for this group of standards. Once again all of the methods were precise in their ability to detect changes in geogenic $\mathrm{C}$ concentration as reflected by high $\mathrm{R}^{2}$ values (Table 5-6). The thermal oxidation at $340^{\circ} \mathrm{C}$ was again the most accurate method because it was the closest to the geogenic $\mathrm{C}$ added line (Table 5-5). An ANCOVA comparison showed no statistical difference between it and the geogenic $\mathrm{C}$ line. 
Table 5-5: Chemi-thermal and thermal oxidation method detection of added coal and shale geogenic $\mathrm{C}$ in manufactured carbonaceous material:soil standards.

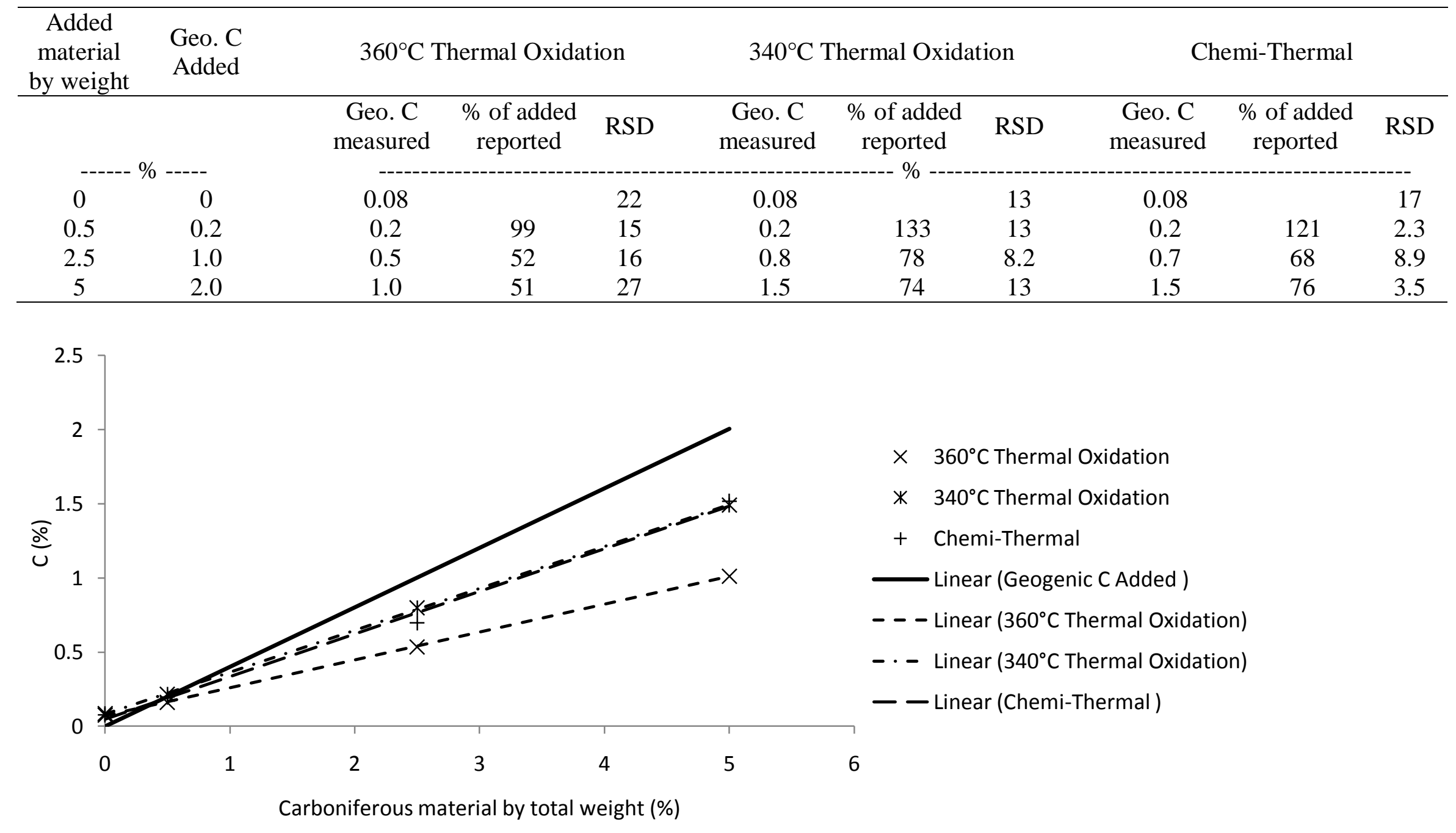

Figure 5-5: Chemi-thermal and thermal oxidation method detection of added coal and shale geogenic $\mathrm{C}$ in manufactured carbonaceous material:soil standards. 
Table 5-6: Linear regression comparison of the chemi-thermal and thermal oxidation methods used to detect added coal and shale geogenic $\mathrm{C}$ in manufactured carbonaceous material:soil standards.

\begin{tabular}{lcc}
\hline & Slope of regression & $\mathrm{R}^{2}$ \\
\hline Geo C added & $0.40 \mathrm{a}$ & 0.999 \\
$340^{\circ} \mathrm{C}$ & $0.29 \mathrm{ab}$ & 0.999 \\
$360^{\circ} \mathrm{C}$ & $0.19 \mathrm{c}$ & 0.999 \\
Chemi-thermal & $0.29 \mathrm{~b}$ & 0.995 \\
\hline
\end{tabular}

* Values in the same column not covered by the same letter are statistically different at $\mathrm{p}=0.05$.

Visual observation showed that there was a difference in how each group of standards responded to washing with $\mathrm{NaOH}$ after the $\mathrm{HF}$ treatment. Figure 5-6 shows the coal group standards arranged in order of the concentration of added geogenic material. There was no visual difference in the clarity of the liquid in these samples suggesting that the HF treatment had little effect on the coal material. However, Figure 5-7 shows the coal and shale group standards. There is an obvious difference in the clarity of these samples with the higher geogenic $\mathrm{C}$ concentration on the left being darker in color. This offers qualitative evidence that this method is releasing geogenic $\mathrm{C}$ from carbonaceous rocks other than coal. 


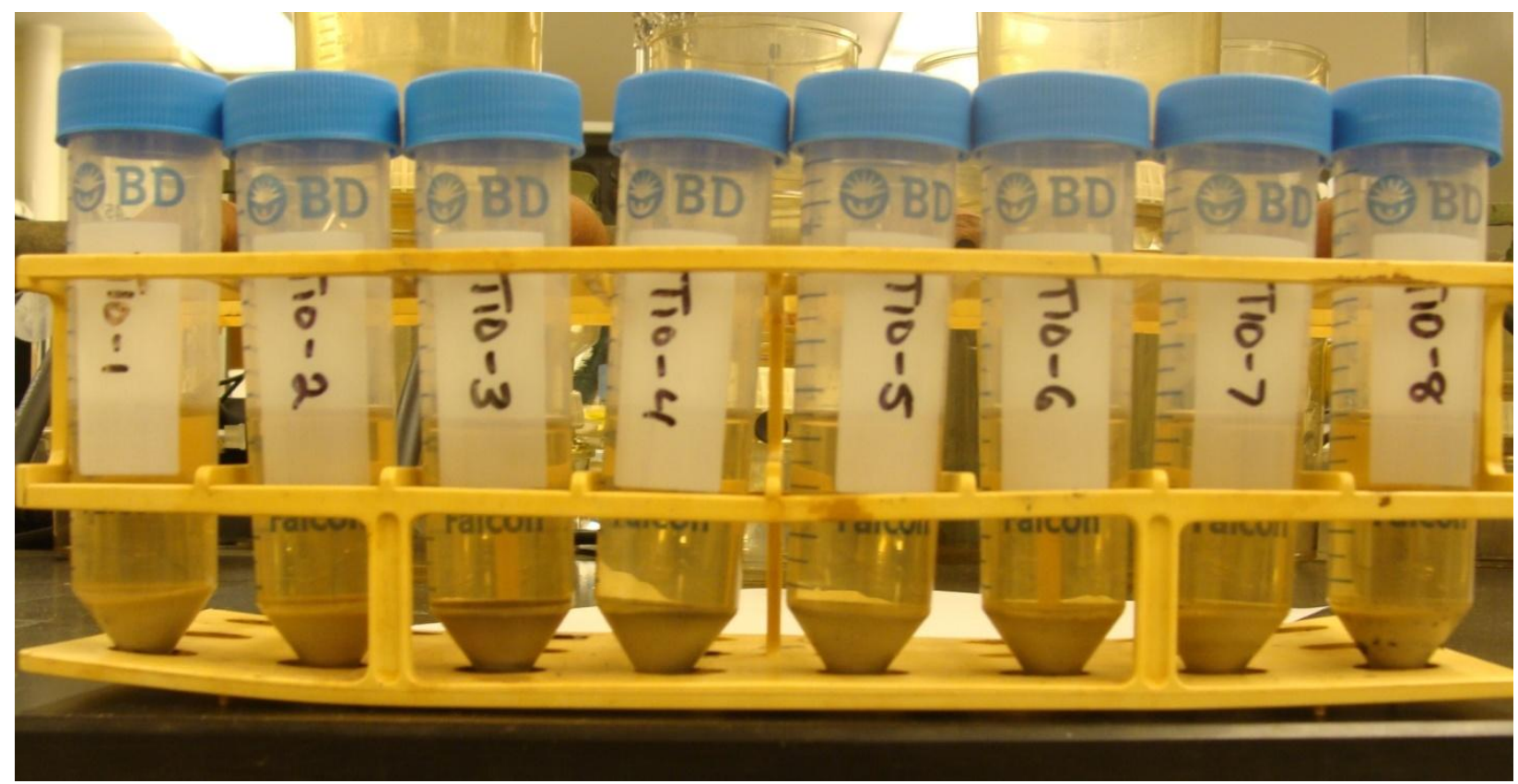

Figure 5-6: No visual change in C after HF treatment while decanting coal group standards.

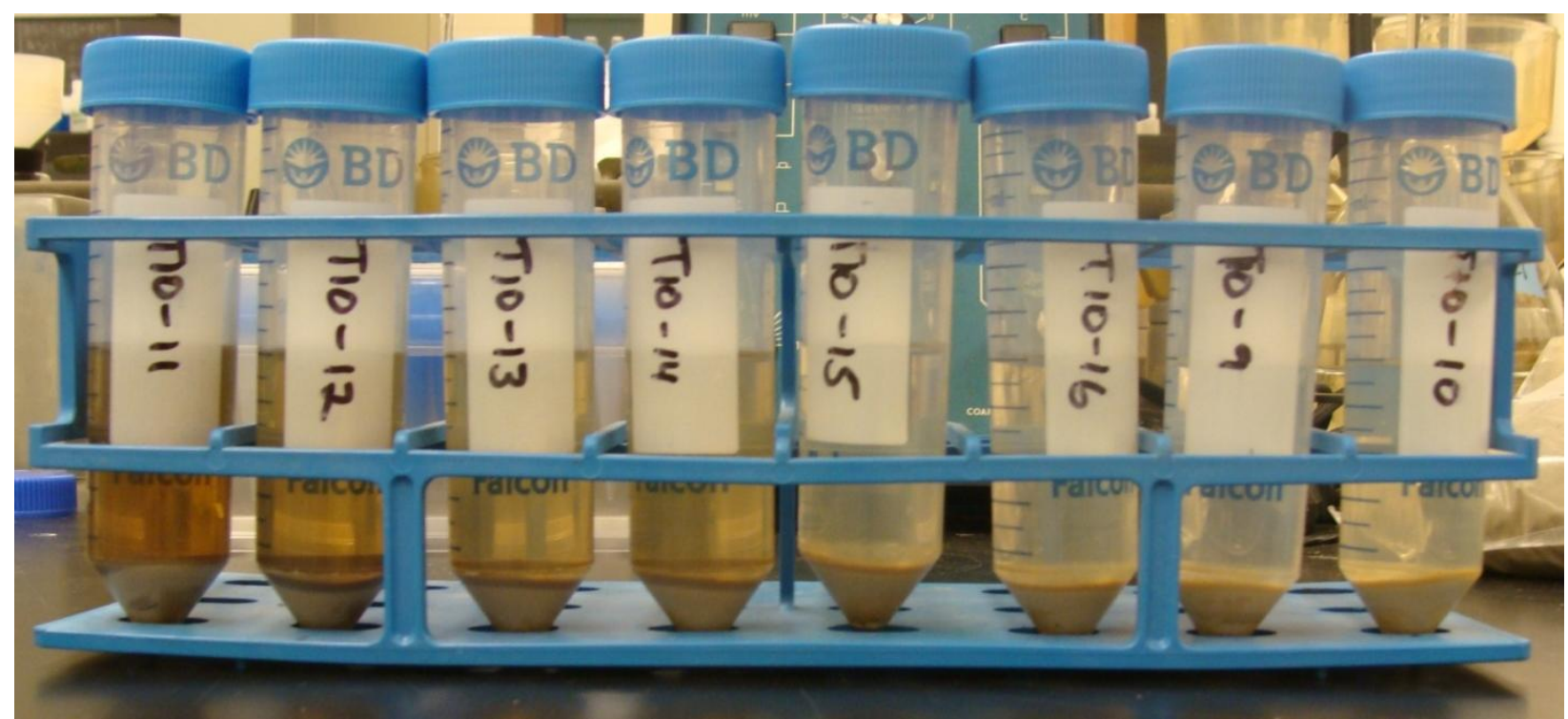

Figure 5-7: Increased $\mathrm{C}$ removal from higher concentrations of coal and shale mixtures observed while decanting coal and shale group standards.

All of the methods used to determine geogenic $\mathrm{C}$ in these standards were typically measuring less than the amount of $\mathrm{C}$ added. As such, since geogenic $\mathrm{C}$ was under reported, pedogenic $\mathrm{C}$ by subtraction was over reported. Removed geogenic $\mathrm{C}$ was greater with increased time and temperature of thermal oxidation for both carbonaceous materials as shown by 
increased separation from the target added geogenic $\mathrm{C}$ line with the more aggressive thermal oxidation step (Table 5-3 and Table 5-5). The fact that the $340^{\circ} \mathrm{C}$ thermal treatment still under reported the correct $\mathrm{C}$ concentration shows that coal and shale materials can still be oxidized at that low temperature. This means that great care should be taken to ensure consistent temperature and time of oxidation during any of these methods.

Ideally, geogenic $\mathrm{C}$ materials would be immune to effects of the chemi-thermal method. If that were the case, accounting for mass loss would correct for the removal of mineral materials and the subsequent enrichment of $\mathrm{C}$ in the sample. For all the samples completed in this manner, the amount of mass retained was typically between $20 \%$ and $60 \%$. Correcting for mass loss would substantially lower the amount of measured geogenic C. As seen from the standards, the chemi-thermal method was already under reporting geogenic $\mathrm{C}$ values for all the standards created. This means that the most accurate values are actually obtained by ignoring the amount of mass loss because both the soil material and the geogenic material are losing mass at the same time.

Carbon pools measured by the chemi-thermal method are, of course, operationally defined which is suitable for comparison purposes. However, given the evidence that the chemithermal method significantly affects geogenic materials found in mine soils, the method seems most suited for qualitative comparisons only. Subsequently, since the chemi-thermal method is unable to provide totally accurate quantitative results for either coal or coal and shale geogenic materials, it would seem that using thermal oxidation to determine geogenic $\mathrm{C}$ is a better choice. In the standards tested, thermal oxidation at $340^{\circ} \mathrm{C}$ for $3 \mathrm{hr}$ produced the most accurate results with far less inputs of time and effort. Although Amichev (2007) reported that thermal oxidation 
of coal was related specifically to the types of minerals in mine soils, it still would appear that thermal oxidation holds promise as an efficient method of determining geogenic $\mathrm{C}$ in mine soils.

\subsection{Conclusions}

A methodological evaluation of the chemi-thermal method of Ussiri and Lal (2008) showed that the method was releasing $\mathrm{C}$ from carbonaceous material. Pure coal was shown to be unaffected by the chemical portion of the method in concurrence with authors' statement that coal was unaltered by the method. However mass and $\mathrm{C}$ were lost during the thermal oxidation step. Carbon was also shown to be released from carbonaceous materials containing shale. This release of geogenic $\mathrm{C}$ would confound efforts to accurately measure pedogenic $\mathrm{C}$ in mine soils. While not quantified, this $\mathrm{C}$ loss highlights some of the shortcomings of the method.

A further comparison of the chemi-thermal method to simple oxidation treatments showed that oxidation at $340^{\circ} \mathrm{C}$ for $3 \mathrm{hr}$ was able to produce more accurate results with far less time and effort to the researcher allowing a greater number of samples to be processed. All of the methods tried, however, did remove some portion of the added geogenic C. To produce truly quantitative results this loss would have to be accounted for in specific mine soils with specific types of geogenic materials. 


\section{Literature Cited}

Akala, V.A. and R. Lal. 2000. Potential of mine land reclamation for soil organic carbon sequestration in Ohio. Land Degrad. Dev. 11:289-297.

Akala, V.A. and R. Lal. 2001. Soil organic carbon pools and sequestration rates in reclaimed minesoils in Ohio. J. Environ. Qual. 30:2098-2104.

Amichev, B. Y. 2007. Biogeochemistry of Carbon on Disturbed Forest Landscapes. PhD dissertation. Virginia Polytechnic Institute, Blacksburg, VA

Bahler, C.C., K.P. Vogel and L.E. Moser. 1984. Atrazine tolerance in warm-season grass seedlings. Agron. J. 76:891-895.

Bendfeldt, E.S., J.A. Burger and W.L Daniels. 2001. Quality of amended mine soils after sixteen years. Soil Sci. Soc. of Amer. J 65:1736-1744.

Bransby, D.I., S.B. McLaughlin and D.J. Parrish. 1998. A review of carbon and nitrogen balances in switchgrass grown for energy. Biomass Bioenergy 14:379-384.

Brejda, J.J. 2000. Fertilization of native warm-season grasses. p. 177-200. In K.J. Moore and B. Anderson (eds.) Native Warm-Season Grasses: Research trends and issues. CSSA spec. publ. 30. CSSA and ASA, Madison, WI.

Chatterjee, A., D.A.N. Ussiri, R.K. Shrestha, and R. Lal. 2009. Soil carbon pools of reclaimed minesoils under grass and forest landuses. Land Deg. \& Devel. 20: 300-307.

Clark, R.B., S.K. Zeto and R.W. Zobel. 1999. Arbuscular mycorrhizal fungal isolate effectiveness on growth and root colonization of Panicum virgatum in acidic soil. Soil Biol. Biochem. 31:1757-1763.

Datar, R.P., R.M. Shenkman, B.G. Cateni, R.L. Huhnke and R.S. Lewis. 2004. Fermentation of biomass-generated producer gas to ethanol. Biotechnol. Bioeng. 86:587-594.

Frank, A.B., J.D. Berdahl, J.D. Hanson, M.A. Liebig and H.A. Johnson. 2004. Biomass and carbon partitioning in switchgrass. Crop Sci. 44:1391-1396.

Gaffney, F.B. and J.A. Dickerson. 1987. Species selection for revegetating sand and gravel mines in the northeast. J. Soil Water Conserv. 42:358-361.

Gee, G.W., and J.W. Bauder. 1986. Particle-size analysis. p. 383-411. In A. Klute (ed.) Methods of Soil Analysis. Part 1. 2nd ed. Agron. Monogr. 9. ASA and SSSA, Madison, WI.

Giuliano, W.M. and S.E. Daves. 2002. Avian response to warm-season grass use in pasture and hayfield management. Biol. Conserv. 106:1. 
Gunter, L.E., G.A. Tuskan and S.D. Wullschleger. 1996. Diversity among populations of switchgrass based on RAPD markers. Crop Sci. 36:1017-1022.

He, Yue, and G. Zhang. 2009. Historical record of black carbon in urban soils and its environmental implications. Environ. Poll. 157: 2684-2688.

Haering, K.C., W.L. Daniels and J.M. Galbraith. 2004. Appalachian mine soil morphology and properties: Effects of weathering and mining method. Soil Sci. Soc. Am. J. 68:1315-1325.

Henning, J. C. 1993. Big Bluestem, Indiangrass and Switchgrass. University of Missouri Extension Publication G4673, University of Missouri Extension, Columbia, MO.

Hitchcock, A.S. 1935. Manual of the grasses of the United States. United States Department of Agriculture, Washington, DC.

Hopkins, A.A., C.M. Taliaferro, C.D. Murphy and D. Christian. 1996. Chromosome number and nuclear DNA content of several switchgrass populations. Crop Sci. 36:1192-1195.

Hultquist, S.J., K.P. Vogel, D.J. Lee, K. Arumuganathan and S. Kaeppler. 1996. Chloroplast DNA and nuclear DNA content variations among cultivars of switchgrass, Panicum virgatum L. Crop Sci. 36:1049-1052.

Jung, G.A., J.A. Shaffer and W.L. Stout. 1988. Switchgrass and big bluestem responses to amendments on strongly acid soil. Agron. J. 80:669-676.

Jung, G.A., J.A. Shaffer, W.L. Stout and M.T. Panciera. 1990. Warm-season grass diversity in yield, plant morphology, and nitrogen concentration and removal in northeastern USA. Agron. J. 82:21-26.

Kort, J., M. Collins and D. Ditsch. 1998. A review of soil erosion potential associated with biomass crops. Biomass Bioenergy 14:351-359.

Kuhlbush, T. A. J. 1995. Method for determining black carbon in residues of vegetation fires. Environ. Sci. Techno. 29:2695-2702.

Lemus, R. and R. Lal. 2005. Bioenergy crops and carbon sequestration. Critical Reviews in Plant Sciences 24:1-21.

Lemus, R., E.C. Brummer, K.J. Moore, N.E. Molstad, C.L. Burras and M.F. Barker. 2002. Biomass yield and quality of 20 switchgrass populations in southern Iowa, USA. Biomass Bioenergy 23:433-442.

Levy, D.B., E.F. Redente and G.D. Uphoff. 1999. Evaluating the phytotoxicity of Pb-Zn tailings to big bluestem (Andropogon gerardii Vitman) and switchgrass (Panicum virgatum L.). Soil Sci. 164:363-375. 
Lewandowski, I., J.M.O. Scurlock, E. Lindvall and M. Christou. 2003. The development and current status of perennial rhizomatous grasses as energy crops in the US and Europe. Biomass Bioenergy 25:335-361.

Ma, Z., C.W. Wood and D.I. Bransby. 2000. Soil management impacts on soil carbon sequestration by switchgrass. Biomass Bioenergy 18:469-477.

McKendry, P. 2002. Energy production from biomass (part 2): Conversion technologies. Bioresour. Technol. 83:47-54.

Moser, L.E. and K.P. Vogel. 1995. Switchgrass, Big Bluestem, and Indiangrass. p. 409-420. In R.F. Barnes, D.A. Miller and C.J. Nelson (eds.) Forages. 5th Ed ed. Iowa State Univ. Press, Ames, IA.

Mulkey, V.R., V.N. Owens and D.K. Lee. 2006. Management of switchgrass-dominated conservation reserve program lands for biomass production in South Dakota. Crop Sci. 46:712-720.

Mulkey, V.R., V.N. Owens and D.K. Lee. 2008. Management of warm-season grass mixtures for biomass production in South Dakota USA. Bioresour. Technol. 99:609-617.

Nelson, D.W. and L.E. Sommers. 1996. Total carbon, organic carbon, and organic matter. p. 961-1010. In A Klute. (ed.) Methods of Soil Analysis. Part 3 - Chemical Methods. Soil Agron. Monogr. 9. ASA and SSSA, Madison, WI.

Nelson, R.G., J.C. Ascough and M.R. Langemeier. 2006. Environmental and economic analysis of switchgrass production for water quality improvement in northeast Kansas. J. Environ. Manage. 79:336-347.

Parrish, D.J. and J.H. Fike. 2005. The biology and agronomy of switchgrass for biofuels. Critical Reviews in Plant Sciences 24:423.

Porter, C.L. 1966. An analysis of variation between upland and lowland switchgrass, Panicum virgatum L., in Central Oklahoma. Ecology 47:980-992.

Rawlins, B.G., S.J. Kemp, P.H. Bellamy, A.M. Tye, C.H. Vane, and A.W. Kim. 2008. Methods for estimating types of soil organic carbon and their application to surveys of UK urban areas. Soil Use and Management 24, no. 1: 47-59.

Rayburn, E. and Lozier, J. 2003. A falling plate meter for estimating pasture forage mass. West Virginia University Extension Service, Morgantown, WV.

Reid, R.L., G.A. Jung and D.W. Hinson. 1988. Nutritive quality of warm season grasses in the northeast. Extension bulletin 699. West Virginia University Agricultural and Forestry Experiment Station, Morgantown, WV. 
Rodgers, C.S. and R.C. Anderson. 1995. Plant growth inhibition by soluble salts in sewage sludge-amended mine spoils. J. Environ. Qual. 24:627-630.

Sanderson, M.A., R.L. Reed, S.B. McLaughlin, S.D. Wullschleger, B.V. Conger, D.J. Parrish, D.D. Wolf, C. Taliaferro, A.A. Hopkins, W.R. Ocumpaugh, M.A. Hussey, J.C. Read and C.R. Tischler. 1996. Switchgrass as a sustainable bioenergy crop. Bioresour. Technol. 56:83-93.

Schmer, M.R., K.P. Vogel, R.B. Mitchell, L.E. Moser, K.M. Eskridge and R.K. Perrin. 2006. Establishment stand thresholds for switchgrass grown as a bioenergy crop. Crop Sci. 46:157-161.

Schmer, M.R., K.P. Vogel, R.B. Mitchell and R.K. Perrin. 2008. Net energy of cellulosic ethanol from switchgrass. Proc. Natl. Acad. Sci. U. S. A. 105:464-469.

Schmidt, M.W.I., and G. Gleixner. 2005. Carbon and nitrogen isotope composition of bulk soils, particle-size fractions and organic material after treatment with hydrofluoric acid. European J. Soil Sci. 3: 407-416

Schmidt, M.W.I., K.M. Prentice, Y. Gelinas, T.A.J. Kuhlbusch, J.O. Skjemstad, C.I. Czimczik, and B. Glaser. 2001. Comparative analysis of black carbon in soils. Global Biogeochemical Cycles 15, no. 1: 163-167.

Shrestha, R.K. and R. Lal. 2006. Ecosystem carbon budgeting and soil carbon sequestration in reclaimed mine soil. Environ. Int. 32:781-796.

Shukla, M.K., and R. Lal. 2005. Temporal changes in soil organic carbon concentration and stocks in reclaimed minesoils of southeastern Ohio. Soil Sci. 170: 1013-1021.

Skeel, V.A. and D.J. Gibson. 1996. Physiological performance of Andropogon gerardii, Panicum virgatum, and Sorghastrum nutans on reclaimed mine spoil. Restor. Ecol. 4:355367.

Skousen, J.G. and C.A. Call. 1987. Grass and forb species for revegetation of mixed soil-lignite overburden in east central Texas. J. Soil Water Conserv. 42:438-442.

Skousen, J.G. and C.L. Venable. 2008. Establishing native plants on newly-constructed and older-reclaimed sites along West Virginia highways. Land Degrad. Dev. 19:388-396.

Staley, T.E., W.L. Stout and G.A. Jung. 1991. Nitrogen use by tall fescue and switchgrass on acidic soils of varying water holding capacity. Agron. J. 83:732-738.

Teel, A., S. Barnhart and G. Miller. 2003. Switchgrass seeding recommendations for the production of biomass fuel in southern Iowa. Iowa State University Extension, Ames, IA. 
Thomason, W.E., W.R. Raun, G.V. Johnson, C.M. Taliaferro, K.W. Freeman, K.J. Wynn and R.W. Mullen. 2004. Switchgrass response to harvest frequency and time and rate of applied nitrogen. J. Plant Nutr. 27:1199-1226.

Tillman, D.A. 2000. Biomass cofiring: The technology, the experience, the combustion consequences. Biomass Bioenergy 19:365-384.

Tober, D., W. Duckwitz, N. Jensen and M. Knudson. 2007. Switchgrass biomass trials in North Dakota, South Dakota, and Minnesota. USDA-NRCS, Bismark, ND.

Tolbert, V.R., D.E. Todd, L.K. Mann, C.M. Jawdy, D.A. Mays, R. Malik, W. Bandaranayake, A. Houston, D. Tyler and D.E. Pettry. 2002. Changes in soil quality and below-ground carbon storage with conversion of traditional agricultural crop lands to bioenergy crop production. Environ. Pollut. 116:S97-S106.

Ussiri, D.A.N., P.A. Jacinthe, and R. Lal. 2006. Post-reclamation land use effects on properties and carbon sequestration in minesoils of southeastern Ohio. Soil Sci. 171: 261-271.

Ussiri, D.A.N., P.A. Jacinthe, and R. Lal. 2006. Soil properties and carbon sequestration of afforested pastures in reclaimed minesoils of Ohio. Soil Sci. 70: 1797-1806.

Ussiri, D.A.N., and R. Lal. 2008. Method for determining coal carbon in the reclaimed minesoils contaminated with coal. Soil Sci. 72: 231-237.

Vassey, T.L., J.R. George and R.E. Mullen. 1985. Early-, mid-, and late-spring establishment of switchgrass at several seeding rates. Agron. J. 77:253-257.

Vogel, K.P. 1987. Seeding rates for establishing big bluestem and switchgrass with preemergence atrazine applications. Agron. J. 79:509-512.

Vogel, K.P. 2000. Improving warm-season forage grasses using selection, breeding, and biotechnology. p. 83-106. In B.E. Anderson and K.J. Moore (eds.) Native warm-season grasses: Research trends and issues. CSSA special pub. no. 30. Crop Science Society of America, Madison, WI.

Vogel, K.P. and H.J.G. Jung. 2001. Genetic modification of herbaceous plants for feed and fuel. Crit. Rev. Plant Sci. 20:15-49.

Wolf, A. and Beegle, D. 1995. Recommended Soil Tests for Macronutrients: Phosphorus, Potassium, Calcium and Magnesium. p. 30-38. In Sims, J.T. and A.M. Wolf (ed.). Recommended Soil Testing Procedures for the Northeastern United States. Northeastern Regional Pub. No. 493 (2nd edition). Agricultural Experiment Station Univ. of Delaware, Newark, DE. 
Wolf, D.D. and D.A. Fiske. 1995. Planting and managing switchgrass for forage, wildlife, and conservation. Virginia Cooperative Extension Pub. no. 418-013. Virginia Cooperative Extension, Blacksburg, VA.

Wright, L., and A, Turhollow. 2010. Switchgrass selection as a "model" bioenergy crop: A history of the process. Biomass and Bioenergy, 34:851-868. 